\title{
Multianalytical Assessment of Armour Paints-The Ageing Characteristics of Historic Drying Oil Varnish Paints for Protection of Steel and Iron Surfaces in Sweden
}

\author{
Arja Källbom ${ }^{1, *}$, Austin Nevin ${ }^{2}$ (D) and Francesca C. Izzo $^{3}$ (D) \\ 1 Department of Conservation, University of Gothenburg, 40530 Gothenburg, Sweden \\ 2 Courtauld Institute of Art, Somerset House, London WC2R ORN, UK; austin.nevin@courtauld.ac.uk \\ 3 Sciences and Technologies for the Conservation of Cultural Heritage, Department of Environmental Sciences, \\ Informatics and Statistics, Ca' Foscari University of Venice, Via Torino 155/b, 30173 Venice, Italy: \\ fra.izzo@unive.it \\ * Correspondence: arja.kallbom@conservation.gu.se
}

check for

updates

Citation: Källbom, A.; Nevin, A.; Izzo, F.C. Multianalytical Assessment of Armour Paints-The Ageing Characteristics of Historic Drying Oil Varnish Paints for Protection of Steel and Iron Surfaces in Sweden. Heritage 2021, 4, 1141-1164. https://doi.org/ 10.3390/heritage 4030063

Academic Editor: Francesco

Paolo Romano

Received: 15 June 2021

Accepted: 3 July 2021

Published: 7 July 2021

Publisher's Note: MDPI stays neutral with regard to jurisdictional claims in published maps and institutional affiliations.

Copyright: (c) 2021 by the authors. Licensee MDPI, Basel, Switzerland. This article is an open access article distributed under the terms and conditions of the Creative Commons Attribution (CC BY) license (https:// creativecommons.org/licenses/by/ $4.0 /)$.

\begin{abstract}
The characteristics of armour paints, historically used to protect ferrous industrial heritage, are explored. Amour paints contain lamellar and highly reflexive pigments of micaceous iron oxide (MIO) and metallic, leafing aluminium, bound in linseed oil and linseed oil-tung oil mixtures, on an inhibitive and soap-forming linseed oil primer (red lead). It is the first study of the binding media used for historical armour paints and investigates the chemical and physical ageing of armour paints using a multianalytical approach. Naturally aged examples are compared to accelerated aged replica armour paint, and to historical paints. The ageing and degradation reactions are assessed by complementary GC-MS and FTIR, together with measurements of wettability, hardness and surface colour. The historical paint formulations include linseed oils and alkyd binders. The results confirm that the leafing effect of aluminium pigments results in only a small concentration of binder at the surface: the paints studied reflect light and form a strong chemical and physical barrier. Linseed oils and tung oil mixtures have been proven to be suitable for the production of armour paints, but the evaluation of ageing and assessment of physical changes will require further investigation.
\end{abstract}

Keywords: armour paint; linseed oil varnish; stand oil; tung oil; anticorrosive paint; aluminum pigments; micaceous iron oxide; ageing; multianalytical characterisation

\section{Introduction}

Ferrous structures are prone to oxidation and corrosion, and organic coatings have long been employed to protect them. Until the mid-20th century, iron bridges, roofing and railings were regularly painted in situ with drying oil varnish coatings to protect them from atmospheric corrosion [1]. These historical paints are believed to provide excellent adhesion to the substrate, high tolerance to existing paint film defects, easy maintenance, high and long-lasting elasticity and weathering resistance. Moreover, they are VOC-free and renewable binder materials. In Sweden, many buildings with original steel sheet roofing, or steel bridges, were and are treated with anticorrosive paints, including socalled "armour paints" (AP), as seen in historical ferrous structures (Figure 1). Recent in situ and empirical investigations of protective coatings based on armour paints from the first half of the 20th century suggest that original coatings exhibit significant weathering resistance $[2,3]$.

The term armour paint, in fact, describes anticorrosive paints that are pigmented with lamellar pigments such as micaceous iron oxide (MIO) and milled leafing metallic aluminum, bound in linseed oil, linseed stand oil and/or tung oil (China wood oil) [1]. AP was traditionally applied in two layers over two layers of primer composed of red lead in linseed oil. Armour paints are known for their high adhesion, density, long-lasting elasticity and high weathering resistance due to the formation of an efficient barrier between the 
substrate and the atmosphere [4-6]. Flaky aluminum pigments are categorised as leafing and non-leafing grades, and the former is used in armour paints [1,7]. "Leafing" indicates that the pigment will float to the coating surface (immediately after application) due to surface tension induced by a fatty acid lubricant used in the production of aluminium and lead to a practically continuous metallic film (resembling close-packed fallen leaves), despite the high density of the metallic pigment $[1,6]$. The thickness of the leafing depends on the pigment and the properties of the binder. The leafing leads to strong reflection of radiation, observed as high gloss [6].

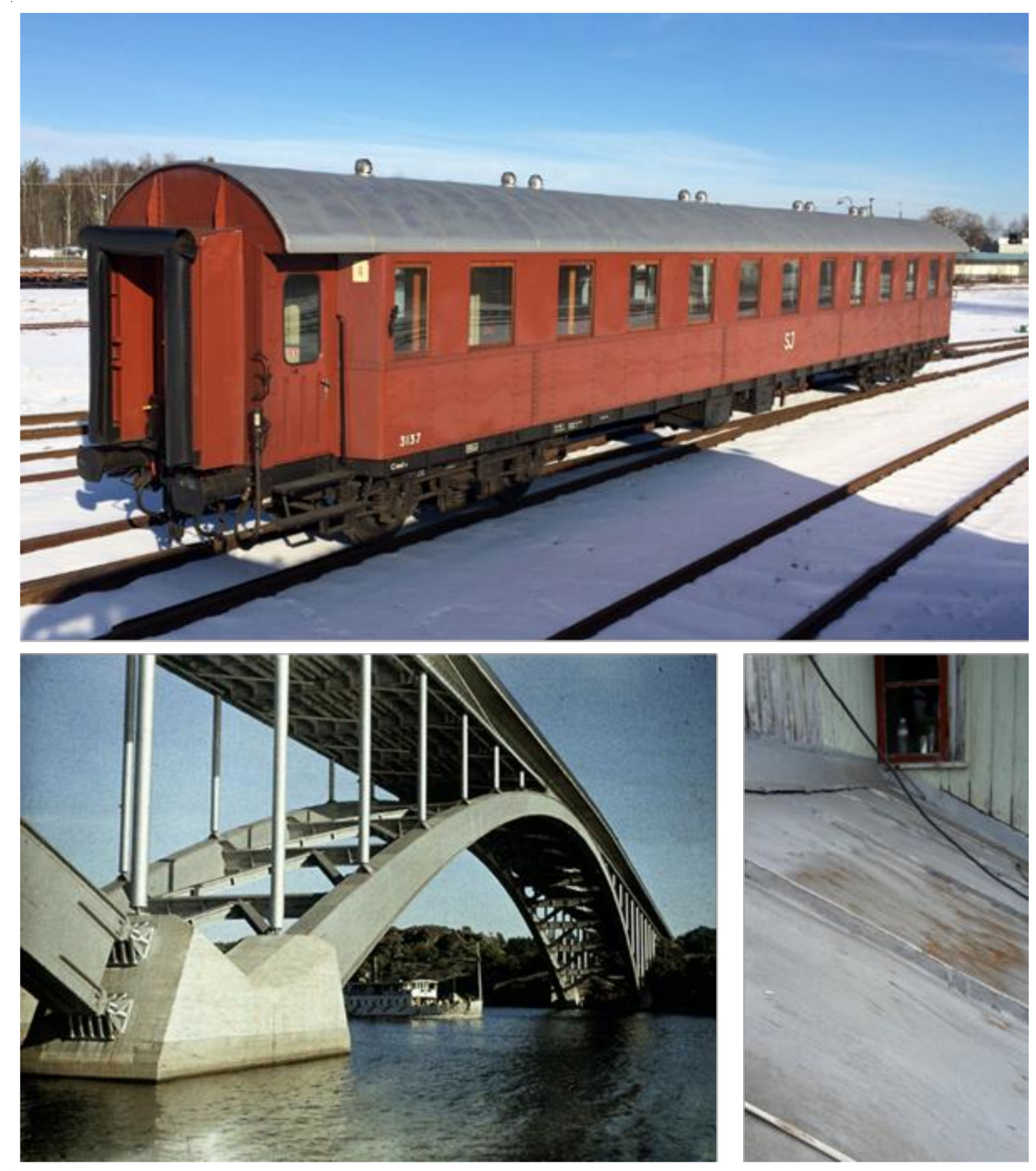

Figure 1. Examples of armour paint on historical ferrous structures. Top: A train wagon from 1936 with armour paint roof. Photo: Anna Lindgren 2019. Left: Västerbron in Stockholm, painted with amour paint in 1936. Photo: Cronquist, Gustaf W:son, unknown year (CC-By). Right: Steel sheet roofing in 2019, last time repainted with armour paint in the 1960s (without primer). Photo: Tom Granath 2019.

Since the 1920s, linseed-based stand oils and tung oils have been used as additives in anticorrosive linseed oil paints as they improve durability and weathering resistance. Tung oil is a pale oil refined from nuts from tung trees and has been known outside of China since 1760 [8]. Tung oil was introduced in paint-making in the late 19th century and was widespread in the 1920s [9]. The high polymerisation rate in tung oil is caused by a $77-86 \%$ content of $\alpha$-eleostearic acid (an 18-carbon chain fatty acid with three conjugated double bonds), which makes the oil very reactive and fast curing [10-12]. Tung oil is the most rapidly drying oil that exists, and refined tung oil is mixed together with other drying oils (such as linseed oil) in order to significantly improve the drying speed, film toughness and water resistance of the paint film $[13,14]$. Linseed stand oil has been produced in the 
Netherlands from the early 19th century $[13,15]$. High-temperature boiling in covered metallic kettles with limited air access, and addition of a drier, results in a pale, polymerised highly bodied oil varnish. It dries with a high and long-lasting gloss and elasticity. The characteristics of this oil are similar to the historically fire boiled linseed oil varnishes, i.e., they have a stand oil character [16]. By contrast, modern "boiled" linseed oils are air-blown with different liquid driers at low temperatures [17]. They are bodied due to preoxidation, rather than thermal polymerisation [9]. Blown varnishes are generally considered as too soft and brittle for producing weathering-resistant films and are also polar, i.e., sensitive to moisture $[14,18]$. It is therefore expected that the blown oil would be more hydrophilic than heat-bodied varnishes, which should be more hydrophobic $[13-15,17,18]$. On the other hand, Kalpers states that blown varnishes work well as binders in aluminium paints [19].

After the Second World War, coatings for ferrous structures and objects based on linseed oil varnishes were gradually replaced with synthetic binders that polymerise and dry with the evaporation of volatile solvents [9]. In the 1990s, the production of linseed oil paints restarted in Sweden, and linseed oil-based paints were reintroduced for heritage applications and in eco-building as environmentally beneficial alternatives to modern synthetic paints.

Modern anticorrosive coatings based on epoxies and polyurethanes are extensively used for anticorrosive maintenance of ferrous substrates today. There is a large variety of these coating systems [20-24]. Despite their advantages, and their ability to form thick barrier coatings, high elasticity and chemical resistance, some drawbacks in their use are related to the use of two-component systems, and the risk of chalking due to atmospheric exposure $[25,26]$. Epoxy-based paints are strongly adhesive and may be particularly difficult to maintain because the removal of aged paint layers requires abrasive blasting that may compromise the integrity of the ferrous substrate. Another objection to these systems is that they are not similar to traditionally used oil varnish paints, which is an important aspect in the maintenance of ferrous heritage, according to international goals formulated by ICOMOS [27-29]. Linseed oils are recognised in scientific publications only as minor modifying additions to different types of modern anticorrosive alkyds or acrylate coatings $[30,31]$ or as minor ingredients in eco-friendly synthesised polyesteramides, epoxies or polyurethanes [32-34]. Due to the increased use of water-based coatings (such as acrylates), contemporary research with aluminium pigmentation has focused on preventing hydrogen formation when the metallic, amphoteric aluminum pigment comes in contact with water [35]. This could be conducted by either treating the pigment surfaces with corrosion inhibitors or by encapsulating them with organic or inorganic coatings [36,37]. This is not a problem when drying oil varnishes are used as binders, as in the historic recipes. Binders with a low acid number, such as kettle-bodied linseed varnishes, have proven to function well over the years, with the leafing effect and colour and luster of the metallic pigments cited as particularly advantageous [38].

The deterioration of oil-based paints affects their visual appearance and protective capacity, due to changes in their physical, chemical and mechanical properties. Photooxidation (UV-light), hydrolysis and thermal exposure, pollutants, increased wet time or UV exposure due to climate changes and so on are recognised factors in oil-based paint degradation [39-41]. The ageing mechanisms for linseed oil paints are well explored for oil paintings in indoor conditions and continue to generate significant research (such as by [42-44]. The role of pigments in paint ageing is also well recognised, as are reactions generated in the ground and at the surface. During the curing and ageing of oil paints, oxidation, formation of volatile compounds and hydrolysis occur, together with physical and mechanical changes. These processes are reported in many studies [45-47].

So far, the study of the behaviour of oil paints in an outdoor environment/condition remains fairly unexplored, in particular on other substrates than painted artworks. There are significant differences in the kinetics and extent of ageing for paintings kept indoors and coated surfaces exposed to outdoor conditions. The latter are exposed to factors such as high UV dosage, high temperatures and humidity fluctuations and long wet 
times, freeze and thaw cycles, the influence of gases and pollutants. In addition, painted ferrous substrates show large movements due to contraction and expansion following large temperature variations and movements of the substrate.

In this context, investigations were conducted in order to explore the chemical and physical properties of replica armour paints and to compare the chemical changes that occur following their exposure to natural and artificial ageing. This work recognises the highly complex mixtures used to prepare armour paints and the need to assess the physical properties of the composite paints.

This work focuses on how historical and reproduced replica armour paints age in natural and accelerated conditions, in order to determine if the paints continue to function for demanding exterior applications. Starting from the investigation of samples from historical structures (four samples from historical armour paints applied to industrial heritage), replicas were prepared with different drying oil binders mixed with inorganic additives in order to investigate the behaviour of these coatings following natural (outdoor) and accelerated ageing. A primer paint remade of red lead bound in linseed oil, with armour paint top coatings, was investigated in two variants and ageing regimes: one with modern low temperature-heated linseed oil varnish (blown oil), and another based on a high-temperature-bodied linseed-stand oil-tung oil mixture (similar to original recipes as reported by [1]). The same inorganic components were added to each paint so that the only variable between the paints was the binding medium. Replica armour paints were then characterised by a multianalytical approach to follow changes during curing and then using a combination of non-invasive and sampling analyses.

\section{Materials and Methods}

\subsection{Overview of Paint Samples}

The paint samples considered as part of this work are listed in Table 1.

Table 1. Description of paint samples.

\begin{tabular}{|c|c|c|c|}
\hline Typology & Name & Object Description & Comment \\
\hline \multirow{4}{*}{ Historical paints } & $\mathrm{OM}$ & $\begin{array}{l}\text { National listed building, } \\
\text { The Oat Mill in Nacka, } \\
\text { Stockholm. }\end{array}$ & $\begin{array}{c}\text { Aluminum pigmented armour paint from a structural } \\
\text { part that has been protected from atmospheric } \\
\text { exposure since } 1934 \text {. The silos were painted with } \\
\text { original armour paints in } 1928 .\end{array}$ \\
\hline & GMW & $\begin{array}{l}\text { A cast iron sign for an } \\
\text { industry; Göteborgs } \\
\text { Mekaniska Werkstad }\end{array}$ & Aluminium pigmented armour paint ca. $1920-1940$. \\
\hline & BJ-red & \multirow{2}{*}{$\begin{array}{l}\text { Bridge in Björneborg } \\
\text { (built 1870) }\end{array}$} & $\begin{array}{l}\text { The original paints have been overpainted (sparkling } \\
\text { top paint beneath, indicating scale armour paint). }\end{array}$ \\
\hline & BJ-grey & & Overpainting. \\
\hline \multirow{3}{*}{ Replica paints } & $\mathrm{F}-\mathrm{Al}$ & \multirow{2}{*}{$\begin{array}{l}\text { Field (outdoor) exposed } \\
\text { armour paints on steel sheet, } \\
\text { in Mariestad, Sweden. }\end{array}$} & $\begin{array}{l}\text { Replica aluminium pigmented armour paint, field } \\
\text { tests started April 2017, outtake in December } 2019 \\
\text { (33 months) and March } 2021 \text { (49 months). }\end{array}$ \\
\hline & F-AP & & $\begin{array}{l}\text { Replica armour paint, field tests started April 2017, } \\
\text { outtake in December } 2019 \text { ( } 33 \text { months) and March } 2021 \\
\text { (49 months). Higher content of MIO, greyish. }\end{array}$ \\
\hline & P1-R & $\begin{array}{l}\text { Artificially aged. } \\
\text { Paint } 1 \text { - solid reference. }\end{array}$ & $\begin{array}{c}\text { Replica paints. Primer of red lead and top layer of } \\
\text { aluminium pigmented armour paint. Blown linseed } \\
\text { varnish as binder. }\end{array}$ \\
\hline
\end{tabular}


Table 1. Cont.

\begin{tabular}{cccc}
\hline Typology & Name & Object Description & Comment \\
\hline & P1-A1 & $\begin{array}{c}\text { Artificially aged. } \\
\text { Paint 1-Aged 1 }\end{array}$ & As above. First outtake 1000 h. \\
\cline { 2 - 4 } Replica paints & P1-A2 & $\begin{array}{c}\text { Artificially aged. } \\
\text { Paint 1-Aged 2 }\end{array}$ & As above. Second outtake 5500 h. \\
& P2-R & $\begin{array}{c}\text { Artificially aged. } \\
\text { Paint 2-solid reference }\end{array}$ & $\begin{array}{c}\text { Replica paints. Primer of red lead and top layer of } \\
\text { aluminium pigmented armour paint. Heat-bodied } \\
\text { linseed oil varnish, stand oil and tung oil mixture } \\
\text { as binder. }\end{array}$ \\
\cline { 2 - 4 } & P2-A1 & $\begin{array}{l}\text { Artificially aged. } \\
\text { Paint 2-Aged 1 }\end{array}$ & As above. First outtake 1000 h \\
\cline { 2 - 4 } & P2-A2 & $\begin{array}{l}\text { Artificially aged. } \\
\text { Paint 2-Aged 2 }\end{array}$ & As above. Second outtake 5500 h. \\
\hline
\end{tabular}

\subsubsection{Historical Paints}

Four paint samples were collected from objects with historical AP layers for analysis (Table 1 and Figure 2). The railway viaduct in Björneborg was currently severely flaking as a result of ageing and repeated overpainting of the original paint. Since this is not a typical ageing characteristic of oil varnish paints (that usually erode), it was assumed that the overpainting had been with other types, such as for instance alkyd paints [1] (Figure 2A,B). The Oat Mill Factory in Nacka is listed by the National Heritage Board as modernistic industrial heritage (Figure 2C,D). The original AP layers from 1928 were eroded on silos, but still intact, prior to repainting in 2016 [3]. The Oat Mill armour paint layers were intact, with a later green overpainting of unknown origin. The grey cast iron sign from a workshop in Gothenburg "Göteborgs Mekaniska Werkstad 1900", with an original aluminium pigmented AP (Figure 2E,F) had been relatively well protected since it was attached to a façade.

\subsubsection{Replica Paints}

Replica paints were produced in cooperation with an experienced professional linseed oil paint manufacturer. In the recipe construction process, a large number of recipes from 1949 (from the archives of $A B$ Förenade Färg) were studied to establish ingredients and proportions, as described by [1]. The historical recipes reveal variations and tailor-made paint formulations. The proportions of the pigments, binders and fillers differed, and there was no universal recipe. Two variants were chosen for accelerated ageing to investigate the role of the binding medium on the performance of the paints. The same formulation was used for the two variants, one with a modern linseed oil binder (Paint 1), and another similar to original recipes (with high-temperature double-boiled linseed oil, stand oil and tung oil mixture) (Paint 2). The pigment-to-binder weight ratio in both armour paints was 0.43 and in the red lead primer 0.80 . For the naturally aged replica armour paints, a number variants were made, with different proportions of pigments. The recipes for primers and armor replica paints are listed in Appendix A. After stepwise addition of pigments and other ingredients to the oils, during continuous blending with a low-speed dissolver the paint mixture was left to be worked for about $60 \mathrm{~min}$. 

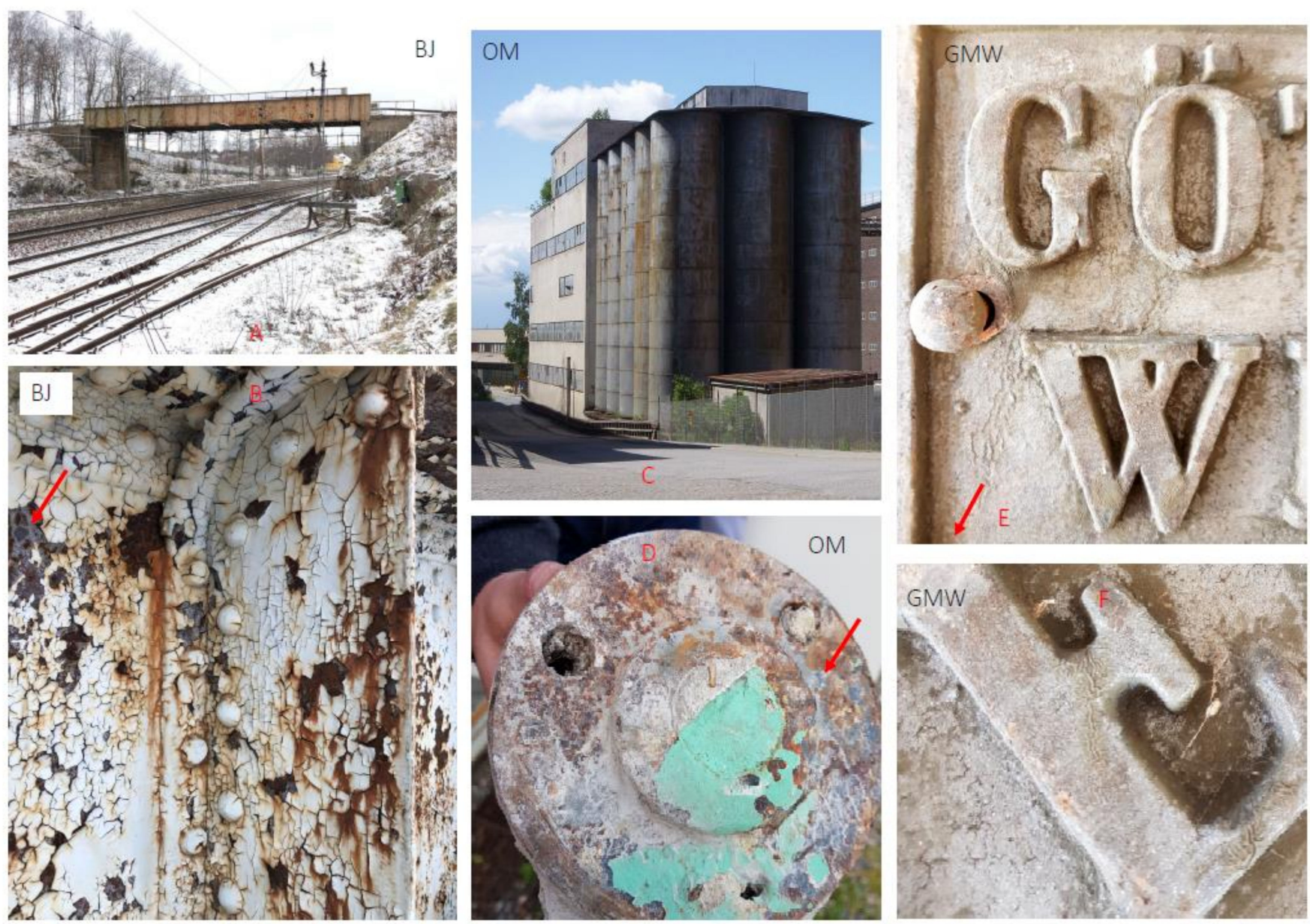

Figure 2. Historical painted surfaces, with the sampling location indicated with a red arrow. Björneborg viaduct (A,B) Oath Mill Factory (C,D), GMW workshop sign (E,F) Photos: Sven-Olof Ahlberg (BJ), Hollger Ellgard (CC-By) (OM Upper), Authors.

\subsubsection{Application of Replica Paints to the Steel Sheet Substrate}

Mild steel sheets, common in steel sheet roofing (Dogal DC10 from SSAB), size $75 \times 95 \mathrm{~mm}$, were used as the substrate for the replica paints P1 and P2. The chemical composition of the steel was C 0.12 wt. \%, Mn max. 0.8 wt. \%, P and S max. 0.045 wt. \%. The steel sheets were degreased with ethanol, rubbed with fine steel wool with detergent to surface profile Ra $6 \pm 1 \mu \mathrm{m}$, washed in water and dried. Directly prior to coating, the surfaces were washed and wiped with ethanol and air dried. Two coats were applied with a fine nylon brush. The thickness of each layer was measured as $30 \mu \mathrm{m}$, first a primer and an armour paint top coat resulting in a total thickness of $60 \mu \mathrm{m}( \pm 3 \mu \mathrm{m})$. To accelerate the ageing mechanisms, it was decided to produce thicknesses which were about half of what is usually applied in practice in Sweden (corrosivity class 2). Paint thickness and surface profiles were determined according to [48,49]. The nylon brushes produced less variation in coating thicknesses compared to tested gap film applicators or drawdown bars. The brush application enabled close contact with the substrate, which is an important aspect of application of linseed oil paints and is most similar to real conditions. Temperature and relative humidity during drying varied between $20^{\circ} \mathrm{C} \pm 1{ }^{\circ} \mathrm{C}$, and relative humidity of $43 \pm 5 \%$. Primer layers were dry to touch within $24 \mathrm{~h}$ and were left to dry for two weeks before one layer of top coat was applied. The red lead primers were covered with a distanced board in order to not expose the samples to light and to reduce the risk of embrittlement. The top coats were touch dry within $24 \mathrm{~h}$ and were left to cure for four weeks before the 
plates were placed into the ageing chamber. Paint-outs of oil films were also prepared without primer and left to cure for four weeks before accelerated ageing started.

\subsection{Ageing Conditions}

\subsubsection{Natural Ageing in Southern Sweden}

In April 2017, a field test with commercial anticorrosive and replica armour paint types, applied on steel sheets, was started in Mariestad in Southern Sweden (Figure 3). Geographically, the city is placed close to the largest lake in the country. The city is small and the corrosivity is estimated to correspond to corrosivity class C2 according to [50].

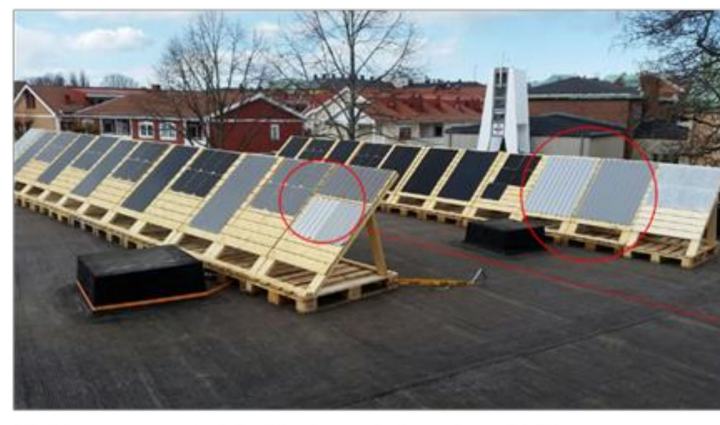

Field tests started in Mariestad, Sweden, 2017.

Substrates: Plane and corrugated steel sheets.

Anticorrosive paints: Various commercial and replica oil varnish paints.

Two aluminium pigmented replica armour paints: $A$ variant with metallic finish (F Al) and a greyish (F AP)
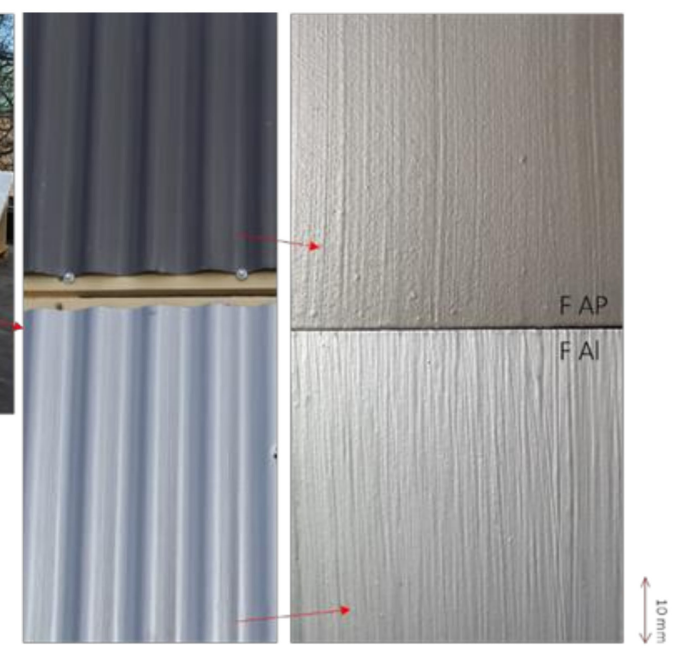

Figure 3. Replica armour paints F-Al and F-AP, naturally aged. Photo: Authors.

\subsubsection{Accelerated Ageing}

Accelerated ageing was carried out in a climate chamber by using a standardised cyclic test [51], Xenotest 440, Atlas Instruments. The ageing did not include salt weathering, and the samples were exposed to controlled cyclic humidity and UV light (Xenon arc lamps with a wavelength distribution similar to daylight) [52]. All parameters were continuously monitored and recorded, including the radiation and efficiency of the Xenon lamps. Although the dosage, moisture and temperature exposure cannot easily be translated to real exposure, $1000 \mathrm{~h}$ exposure of the standardized testing procedure may be equated with approximately one year (southern facing) in the climate in Southern Sweden, Corrosivity Class $\mathrm{C} 2$ according to $[2,50,53]$. Three samples of each replica paint (P1 and P2) were placed in the climate chamber. The samples were checked and were assessed for chalking using the tape test according to [54]. A surface profile measurement with Elcometer 224 was made per sample, 30 measurements each sample. The first sample was removed when most of the paint surfaces had become visibly matte (approximately $1000 \mathrm{~h}$, UV dosage $1500 \mathrm{~kJ}$ ). A second sample was removed after $5500 \mathrm{~h}$ (UV dosage 20,000 kJ, equivalent to about five years natural exposure according to [53], when discolouration started to appear on the chalking paint surfaces.

\subsection{Investigations and Analytical Methods \\ 2.3.1. König Pendulum Hardness Rocker}

Hardness is an indication of the polymer's elastic modulus, yield strength and strain hardening ability. Hardness measurements could give an indication of the relative embrittlement of the aged surfaces, due to oxidation [55]. A König pendulum hardness measurement was conducted according to [54] for all plates at room temperature in the laboratory. This method is widely used for hardness testing of polymers and coatings [56]. Up to seven measurements were made per replica samples P1 and P2, and the average, standard deviation $\left(\mathrm{S}_{\mathrm{d}}\right)$ and cumulative percentage change was calculated. 


\subsubsection{Contact Angle Measurements (Wettability)}

One drop of water was deposited on the surface of the replica samples P1 and P2 and an image of it was taken through a portable microscope positioned perpendicularly to the surface and fixed on a support. Distilled water was dropped on the surfaces with pipette in order to check the wettability of the painted surface by observing the appearance of the droplets. Evaluation of the $\theta$ angle (which is the angle formed between the surface of the sample and the lowest part of the drop, when contact between the objects is established) was carried out with the software DinoCapture2.0 version 1.3.7.A. The presented value is the average of three replicas.

\subsubsection{Colourimetry}

To study the chromatic variations (in the CIEL* $\mathrm{a}^{*} \mathrm{~b}^{*}$ space) which occurred during the ageing of the replica paint samples P1 and P2, a Konica Minolta CM 2600d/2500d spectrophotometer was employed. The measurements were performed in SCI (specular component included) and SCE (specular component excluded) modality. The spectrophotometer has an 8-degree viewing angle geometry, with a Xenon lamp diffusion light and a high-resolution monolithic polychromator. The instrument analysed circular areas with an average diameter of $3 \mathrm{~mm}$; each acquired result was the average of three consecutive measurements made in the same point. The recorded data were elaborated by the software Spectra Magic NX.

\subsubsection{Fourier Transform Infrared Spectroscopy}

Analysis of (unaged and aged) replica paints $\mathrm{P} 1$ and P2, and their binders, was carried out by Fourier transform infrared spectroscopy (FTIR). An Alpha, Bruker Optics FTIR spectrometer was used in attenuated (ATR) and external reflectance (ER) mode. The spectrometer was equipped with a $\mathrm{Pt} / \mathrm{SiC}$ globar source, a Rock-solid interferometer (with gold mirrors) and a deuterated triglycine sulphate (DLaTGS) detector, operating at room temperature, giving a linear response on the spectral range between 7500 and $375 \mathrm{~cm}^{-1}$. Measurements were carried out by a front reflection module (Alpha-R) with an optical layout of $22^{\circ}$. Pseudo-absorption spectra $(\log ((1 / R)) ; R=$ reflectance) were acquired with working distance of $15 \mathrm{~mm}$ (large distance holder), from a sampling area of about $20 \mathrm{~mm}^{2}$ in the spectral range of $4000-400 \mathrm{~cm}^{-1}$, at a resolution of $4 \mathrm{~cm}^{-1}$ and using 120 scans. Spectra from a gold mirror were used as background. For measurements in ATR mode on micro-samples from the surface, a diamond crystal was used, with resolution of $4 \mathrm{~cm}^{-1}$ and 128 scans.

\subsubsection{Gas Chromotography-Mass Spectrometry}

According to a derivatisation method already tested on fatty acids from oil-based paints [47,57-62] lipids contained in small amounts of paint samples (weight ranging from 0.10 to $0.20 \mathrm{mg}$ ) were transformed into their corresponding methyl esters by a one-step transesterification using $50 \mu \mathrm{L}$ of $\mathrm{m}$ (trifluoromethylphenyl)trimethylammonium hydroxide, $2.5 \%$ in methanol, overnight reaction at room temperature. One microliter of each derivatised sample was automatically injected by an autosampler AS1310 (Thermoscientific) in a Trace GC 1300 system (Thermoscientific) equipped with a mass spectrometric detector ISQ 7000 with a quadrupole analyser (Thermoscientific). The chromatographic separation was performed on a chemically bonded fused silica capillary DB-5MS Column (30 m length, $0.25 \mathrm{~mm}, 0.25 \mu \mathrm{m}-5 \%$ phenyl methyl polysiloxane), using helium as the carrier gas (flow rate $1 \mathrm{~mL} / \mathrm{min}$ ). The inlet temperature was $280^{\circ} \mathrm{C}$, and the MS interface was at $280{ }^{\circ} \mathrm{C}$. The transfer line was at $280^{\circ} \mathrm{C}$ and the MS source temperature was $300{ }^{\circ} \mathrm{C}$. The temperature program was set from 50 to $320^{\circ} \mathrm{C}$ with a ramp of $10{ }^{\circ} \mathrm{C} / \mathrm{min}$, held at the temperature for $5 \mathrm{~min}$. The MS was run in full scan mode $(\mathrm{m} / \mathrm{z} 40-650), 1.9$ scans $/ \mathrm{s}$. Electron ionisation energy was $70 \mathrm{eV}$. The compounds were identified by comparison with the NIST and MS Search 1.7 libraries of mass spectra and a library created by the authors. Quantitative analysis was achieved using nonadecanoic acid as the internal standard and a 
standard solution containing saturated (myristic, palmitic, stearic, azelaic, suberic, sebacic) and unsaturated (oleic, linoleic, linolenic, palmitoleic) fatty acids and glycerol. The molar ratios among the most important fatty acids were calculated: A/P (azelaic to palmitic acid ratio), $\mathrm{D} / \mathrm{P}$ (dicarboxylic acid to palmitic acid ratio) and $\mathrm{D} \%$ (total percentage of dicarboxylic acid) to provide information on the degree of oxidation of oil; $\mathrm{P} / \mathrm{S}$ (palmitic to stearic acid ratio) is commonly used to suggest the type of drying oils; $\mathrm{O} / \mathrm{S}$ (oleic to stearic acid ratio) may indicate the maturity of oils (i.e., the amount of remaining unsaturated fatty acids) [57].

\section{Results and Discussion}

\subsection{Organic Composition of Historical Samples}

The historical paint samples were characterised to determine the composition of the binding media employed. To the best of our knowledge, this is the first study that considers historical cases of the application of armour paints.

ER-FTIR analysis was followed by GC-MS analysis. It is important to note that, while the former analyses give information related to the superficial painted layers, GC-MS results tell us about the paints in bulk.

Figure 4 illustrates the ER-FTIR spectrum of the BJ sample, which highlights the presence of a significant organic fraction, identified as lipidic-based compounds. The IR spectrum, indeed, was characterised by the typical vibrations due to the stretching $-\mathrm{CH}_{2} \mathrm{CH}_{3}$ at 2930 and $2856 \mathrm{~cm}^{-1}$, and the stretching $\mathrm{C}=\mathrm{O}$ at $1747 \mathrm{~cm}^{-1}$, respectively corresponding to the hydrocarbon chains and the carboxylic groups preset in oil-binding media.

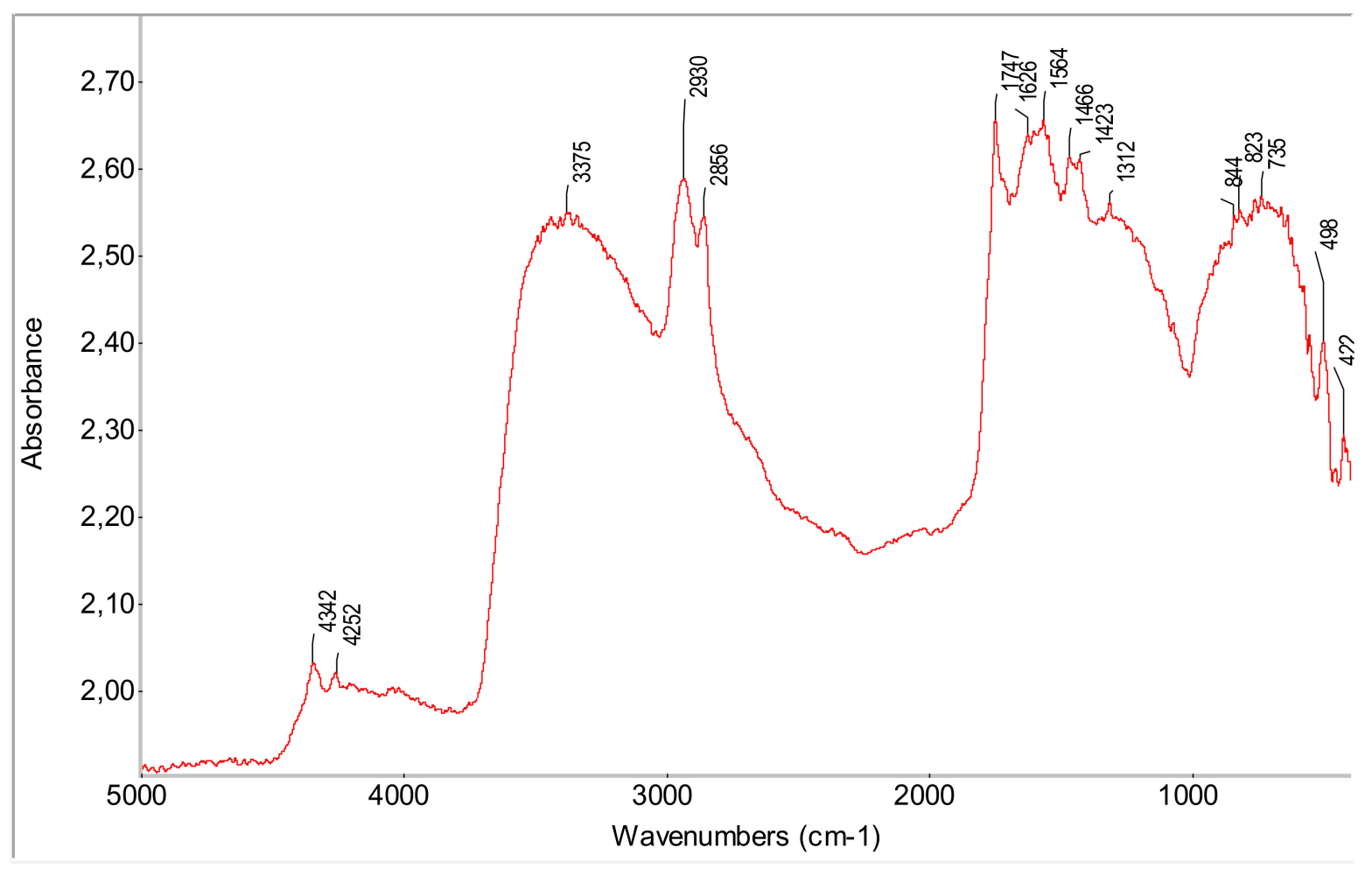

Figure 4. ER-FTIR of historic paint layer from the bridge in Björneborg (BJ).

Furthermore, the peak at $1564 \mathrm{~cm}^{-1}$ was related to the presence of metal carboxylates (i.e., metal soaps) [63-65]. These compounds can form from the lipidic polymerised matrix (upon hydrolysis of the original oil film) and the reaction of (free) fatty acids with cations (generally from pigments and/or additives in paint mixtures). In modern and contemporary oil paint formulations, they are also commonly added as dispersion agents (i.e., aluminium and other metallic stearates) $[57,58,61]$. 
Considering that traditional armour paints are made with a mixture of lipid binders and metallic pigments/metal powders and that there is also the presence of a leadcontaining primer, the occurrence of metallic soaps is not surprising. It remains to be determined, in historical cases, whether the metal soaps were additives in the form of stearates [6] and Appendix A for pigment manufacturer) or if the soaps were the result of reactions within the paint.

GC-MS results on micro samples confirmed that the historical case studies were painted with drying oils. Except for one case (as described below), the chromatograms were characterised by the typical fatty acid profile of aged oil-based paints: saturated monocarboxylic acids (mainly palmitic and stearic acids) and saturated dicarboxylic acids (pimelic, suberic, sebacic and azelaic, the last being the most abundant) were largely detected in the paint samples together with glycerol and traces of unsaturated (oleic) acids.

The fatty acids detected in the analysed painted layers and their percentages are stated in Appendix B and exemplified in Figure 5. Quantitative results were obtained for saturated acids (monocarboxylic acids such as myristic, palmitic, stearic; dicarboxylic acids such as pimelic, suberic, azelaic, sebacic), unsaturated fatty acids (oleic, linoleic and linolenic acids) and glycerol. Several oxidation by-products, other fatty acids and other compounds were identified qualitatively. The most significant molar ratios and the total percentage of dicarboxylic acids $(\% \mathrm{D})$ are reported as well and help in elucidating the composition of the historical armour paints.

The values of $\% \mathrm{D}$, related to the typical oxidation products from unsaturated fatty acids present in fresh vegetable drying oils, is generally higher than $35 \%$ in weight and the ratio between azelaic and palmitic acid $(\mathrm{A} / \mathrm{P})$ is a ratio $>1$ for all the analysed paints. Besides dicarboxylic acids, other oxidation products were identified in the samples, such as oxo-, hydroxy- and methoxy- octadecanoic acids, produced by the oxidative scission of unsaturated fatty acids [43]. Additionally, indicative of oxidation mechanisms was the presence of only trace amounts of oleic acid, which together with other double and triple unsaturated fatty acids (linoleic and linolenic acids for linseed oil and linoleic and alpha-eleostearic acid for tung oil) make up more than $66-80 \%$ of the fatty acids in fresh films. In the studied armour paints, the $\mathrm{O} / \mathrm{S}$ ratios were lower than 0.4 . To identify the kind of oil, the ratio between palmitic and stearic acid $(\mathrm{P} / \mathrm{S})$ is generally taken into consideration. According to specific literature, we can state that $\mathrm{OM}(\mathrm{P} / \mathrm{S}=1.1)$ and BJred $(\mathrm{P} / \mathrm{S}=1.5)$ paints are bound with linseed oil [43,46,57].

It is not possible to determine whether tung oil was also present in the original recipes, as the high reactivity of the unsaturations means that the fatty acid profile in aged films made with linseed oil or tung oil are quite similar, as reported by [12].

Different is the case of GMW paint, where the P/S was 0.5 , indicating a major amount of stearic acid, most likely due to the presence of formed and/or added metal stearates in the painted layers, as previously discussed.

The greyish overpainting of the original red layer (probably primer paint) in the Bridge at Björneborg was painted using an oil-modified alkyd paint. According to the GC-MS results, the typical fatty acids present in dried linseed oil $(\mathrm{P} / \mathrm{S}=1.3)$ were detected together with the characteristic alkyd-based varnish (phthalic acid, pentaerythritol and benzoic acid, in particular) [66]. This indicates that the bridge was painted in the mid-20th century when alkyds were more widely used. 


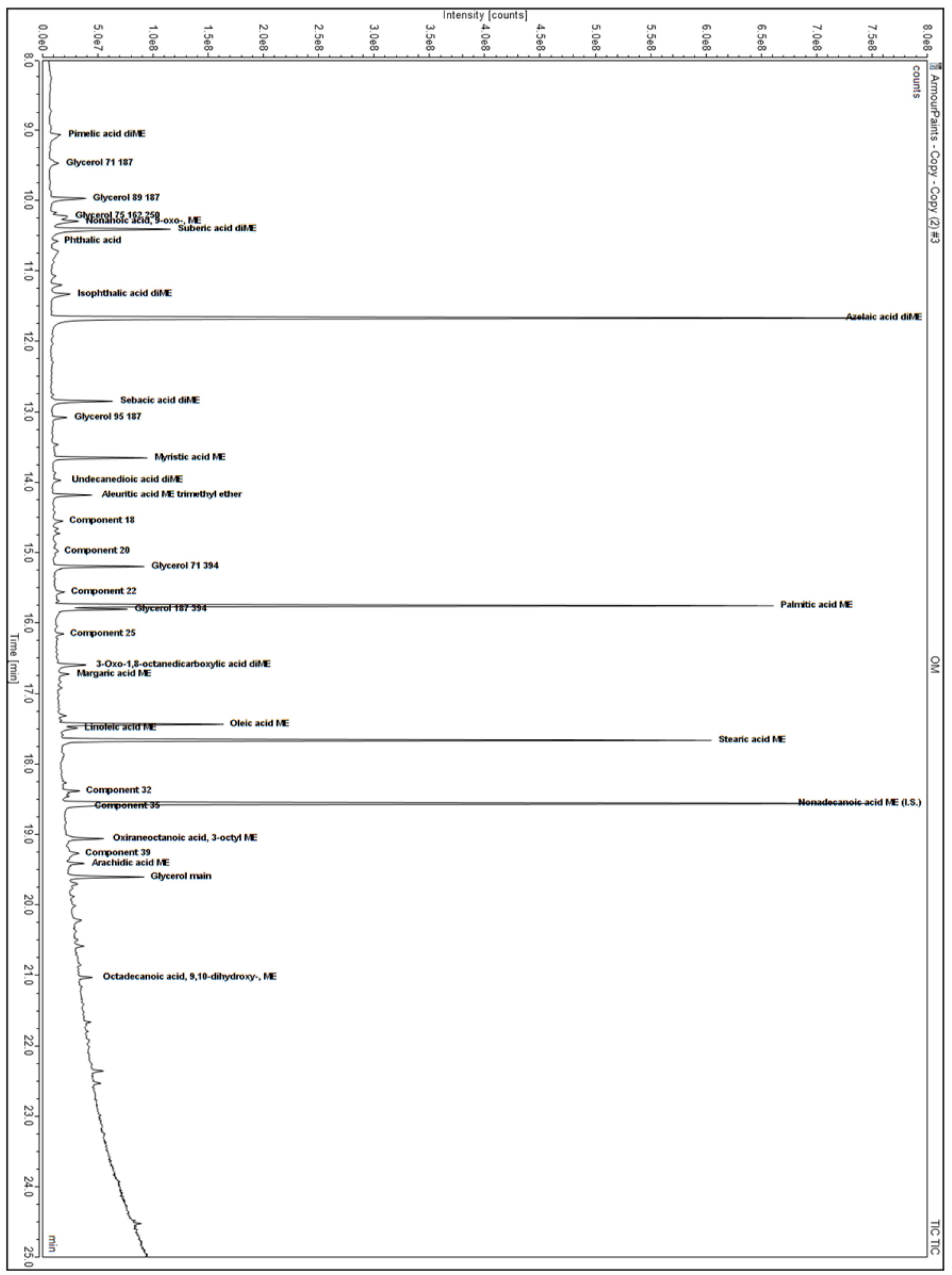

Figure 5. Total ion current (TIC) chromatogram of historical paint sample from the Oat Mill (OM) after derivatisation and GC-MS analysis. Fatty acids were identified as methyl esters (ME) or dimethyl esters (diME); glycerol was identified in different derivatives. 


\subsection{Replica Paints}

\subsubsection{Natural Ageing}

Field-exposed armour paints on steel sheet (F-AI and F-AP) were subjected to outdoor natural ageing, as described in Section 2.2.1. The samples removed in December 2019 and March 2021 had been facing south for approximately 23,880 and 35,400 h (i.e., 33 and 49 months) of natural exposure. The impact of these conditions was assessed through macroscopic observations, contact angle measurements (wettability), ER-FTIR and GC-MS analysis.

Macroscopically both naturally aged replica amour paints were in perfect condition by the time of outtake, and no visible deterioration (cracking, delamination, paint losses) was detected. This suggests that the physical properties of the films were satisfactory, and the binder proportions were about the same in the paint formulation. The grey AP (F AP) was slightly more dirty, probably due to the higher proportion of micaceous iron oxide: this pigment, indeed, was quite coarse, and the paint surface had collected deposits more easily compared to the smoother aluminium pigment-rich variant $(\mathrm{F} \mathrm{Al})$.

The contact angle measurements on the painted surface provide important indications of changes in the wettability of the studied system. It is interesting to note that the 2019 F-AI and F-AP replicas had contact angle values around 55-60 , thus typical of a "good wetting" condition, while in 2021 the values increased up to about $90^{\circ}$ (incomplete wetting), as shown in Figure 6. We would expect an oil paint to have a higher hydrophobicity before ageing and then a higher hydrophilicity after ageing. However, experimental data show that this is not the case [67] have shown that surface wettability of oil varnish paints for wood is time-dependent. Tung oil additions to paint rapidly turn hydrophobic due to the rapid polymerisation of tung oil, but linseed oil varnishes show higher hydrophobicity (higher wetting angle) after a longer induction period. The current measurements may therefore indicate that these paint layers were still immature (see in fact the abundant presence of oleic acid detected by GC-MS analysis) and therefore it will be necessary to monitor over time when this transition will take place in terms of wettability. Another possibility is that the very thin organic surface fraction that was present on the surface, due to the leafing effect of the aluminium paint, was modified during ageing, and the increasing hydrophobicity was a result of changing surface energy due to a more highly exposed metallic surface. It is also known that changes in surface roughness could affect the contact area and contact angle [68]. An ageing surface that chalks will become smoother, which may result in a higher wetting angle.

FTIR analyses were conducted in ATR mode on paint fragments. For both the 2019 and 2021 F-AI and F-AP series, samples were analysed both "externally" (i.e., resting on the ATR diamond crystal on the outer surface) and at the inner interface in contact with the primer layer. 
F Al 2019
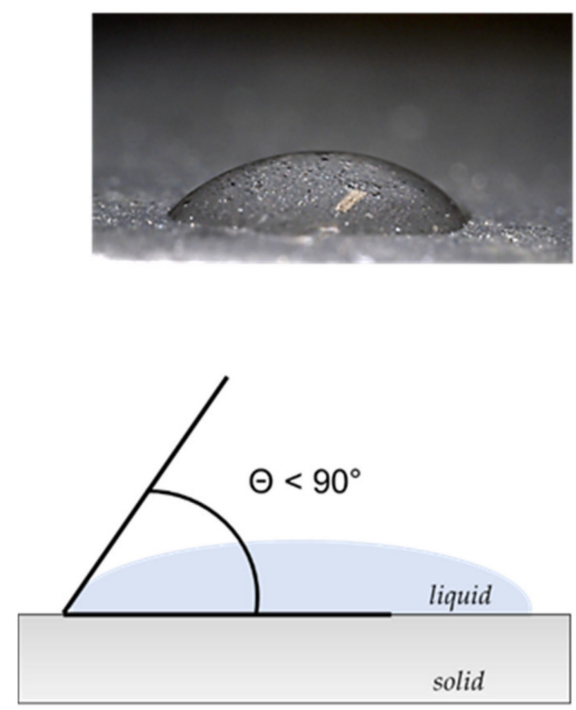

Hydrophilic, good wetting
F Al 2021

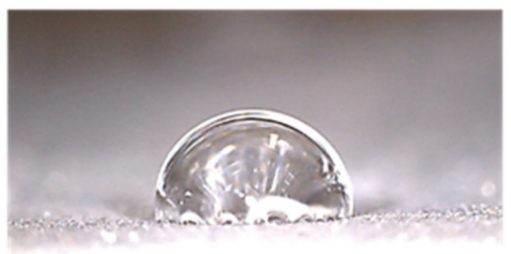

$\odot>90^{\circ}$

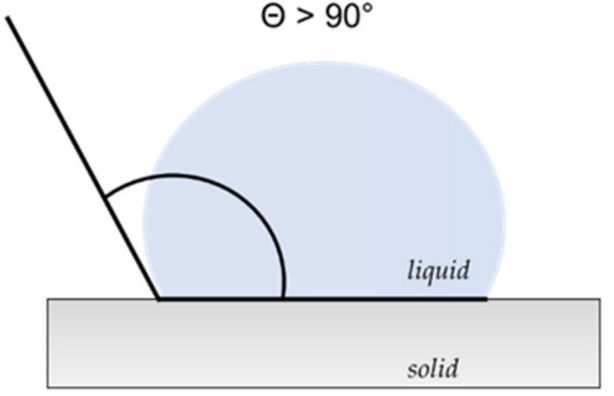

Hydrophobic, incomplete wetting

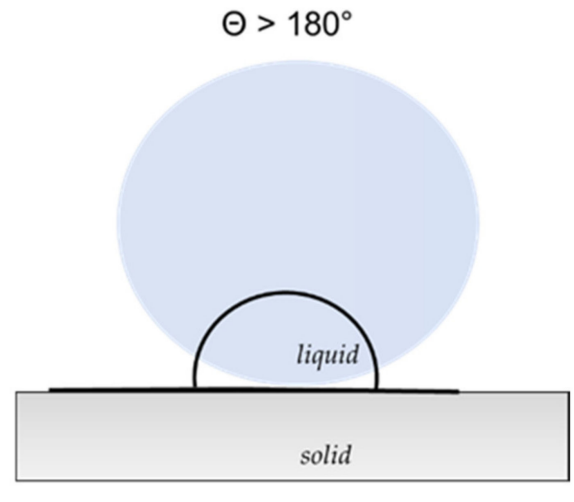

Hydrophobic, complete non-wetting

Figure 6. Wettability of naturally aged F-Al 2019 and 2021.

In this way it was possible to verify that:

- Externally, the IR analysis was strongly influenced by the inorganic and reflective pigments that were highly reflective and there was little appreciable signal from molecular vibrations from the binder (shown in green in Figures 7 and 8).

- In the interface between armour paint and lead-containing primer, instead, the organic component was present and visible in the IR spectra (shown in red in Figures 7 and 8). In addition to the typical peaks related to the use of a lipidic binder, the absorptions due to metal carboxylates were clearly visible (in particular the peak very defined at $1566 \mathrm{~cm}^{-1}$ ).

As an example, the FTIR-ATR spectra of F-AP 2019 and F-AI 2021 samples are shown in Figures 7 and 8.

The detection of metal carboxylates could also be explained considering that the replica paints also contained reactive $\mathrm{ZnO}$ (Appendix $\mathrm{A}$ ). $\mathrm{ZnO}$ is well known to promote the formation of metal soaps when mixed with lipidic binding media (Osmond 2012). For anticorrosive paints, the zinc soaps are generally considered as beneficial since the elasticity and density of the paint films are improved with the addition of $\mathrm{ZnO}$ [69].

GC-MS provided significant information related to the chemical changes due to natural ageing conditions. As for the historical paint samples, the chromatograms from F-AI and F-AP replica paints were characterised by the typical fatty acid profile of (dried) drying oils: in both series, the most abundant fatty acids were palmitic, stearic azelaic, suberic, sebacic and oleic. 


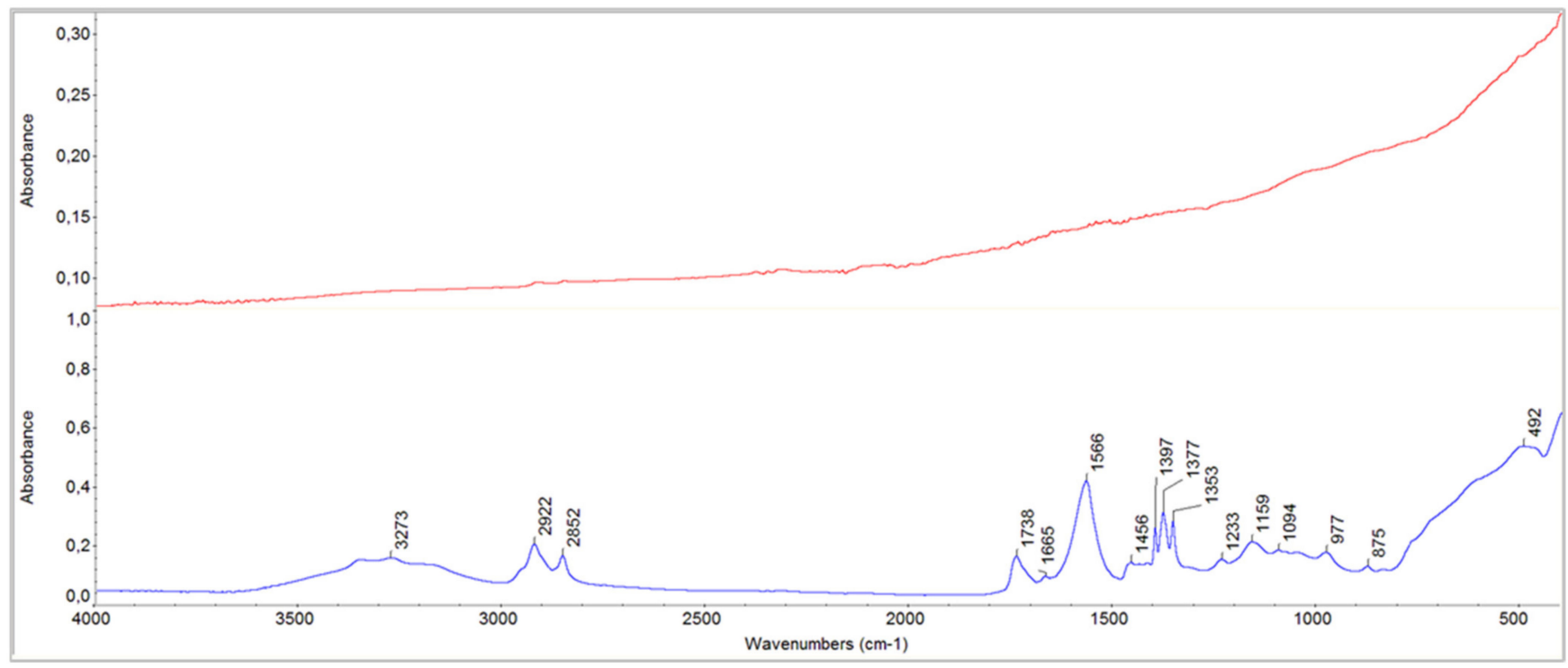

Figure 7. FTIR-ATR spectra of the F-AP 2019 paint sample: external (blue) and internal surface (red).

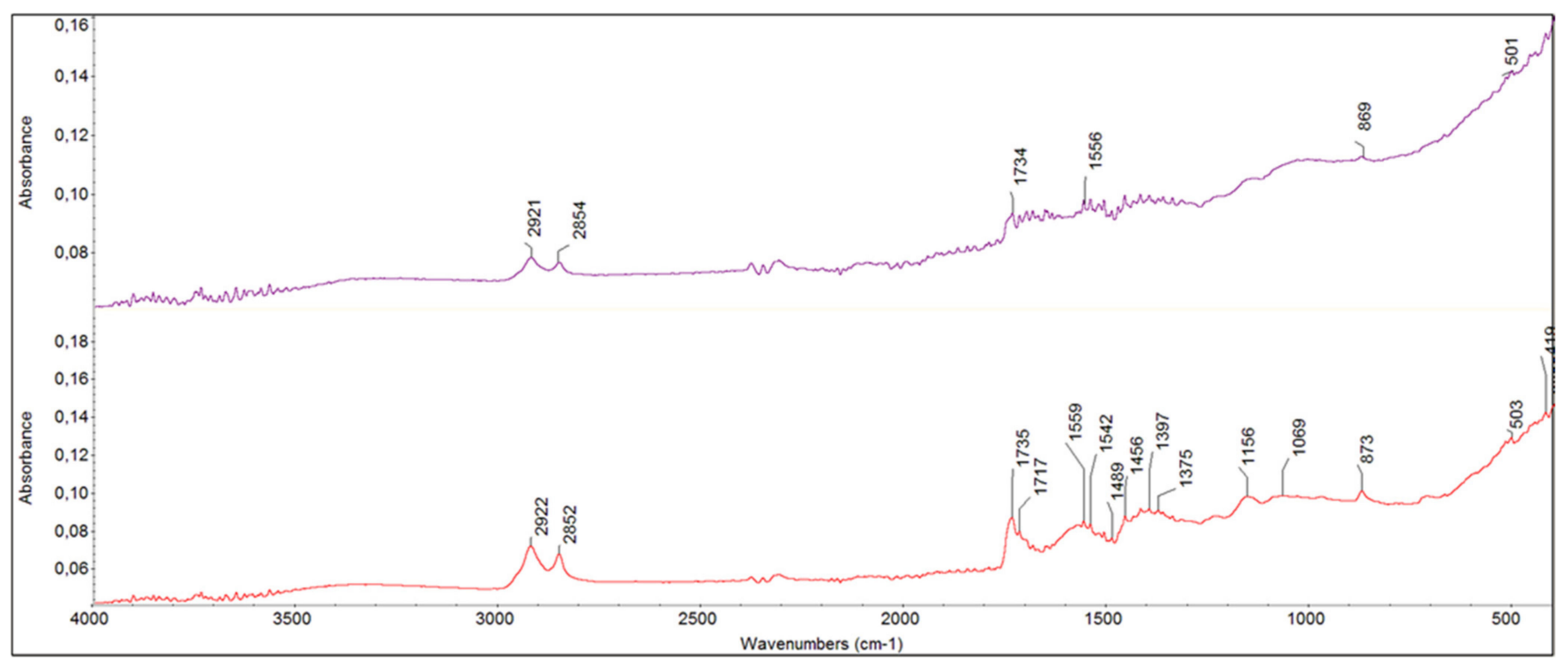

Figure 8. FTIR-ATR spectra of the F-AI 2021 paint sample: external (violet) and internal surface (red).

However, the fatty acids percentage varies if we consider the first outtake (2019) and the second (2021). In fact, as is known with ageing, the mechanisms of auto-oxidation, polymerisation, cross-linking and hydrolysis lead to compositional changes that are sometimes significant from both a qualitative and a quantitative point of view. In particular, there is an increase in the percentage of dicarboxylic acids $(\% \mathrm{D})$ and a decrease in the concentration of unsaturated fatty acids. In addition, there is usually a significant presence of oxidation compounds.

In the case of F-AI and F-AP paints, these changes have also been recorded in Figure 9. For example, in 2019 the F-AI paint counted a \%D value of 30.9, which increased to 36.9 in 2021, while the concentration of oleic acid was still very pronounced. Similar is the case of FAP paint. A conspicuous presence of an unsaturated fatty acid such as oleic acid can be explained by the youth of the film and by the minor reaction to autoxidation compared to doubly (linoleic) and triply (linolenic, $\alpha$-eleostearic acid) unsaturated acids [43,70]. Moreover, the influence that the metallic component of the paint mixture can have on the organic fraction should not be forgotten. In fact, if on the one hand the catalytic action of 
many metal ions is known, it is also true (as mentioned before) that some compounds such as $\mathrm{ZnO}$, can "trap" oleic acid [71,72].

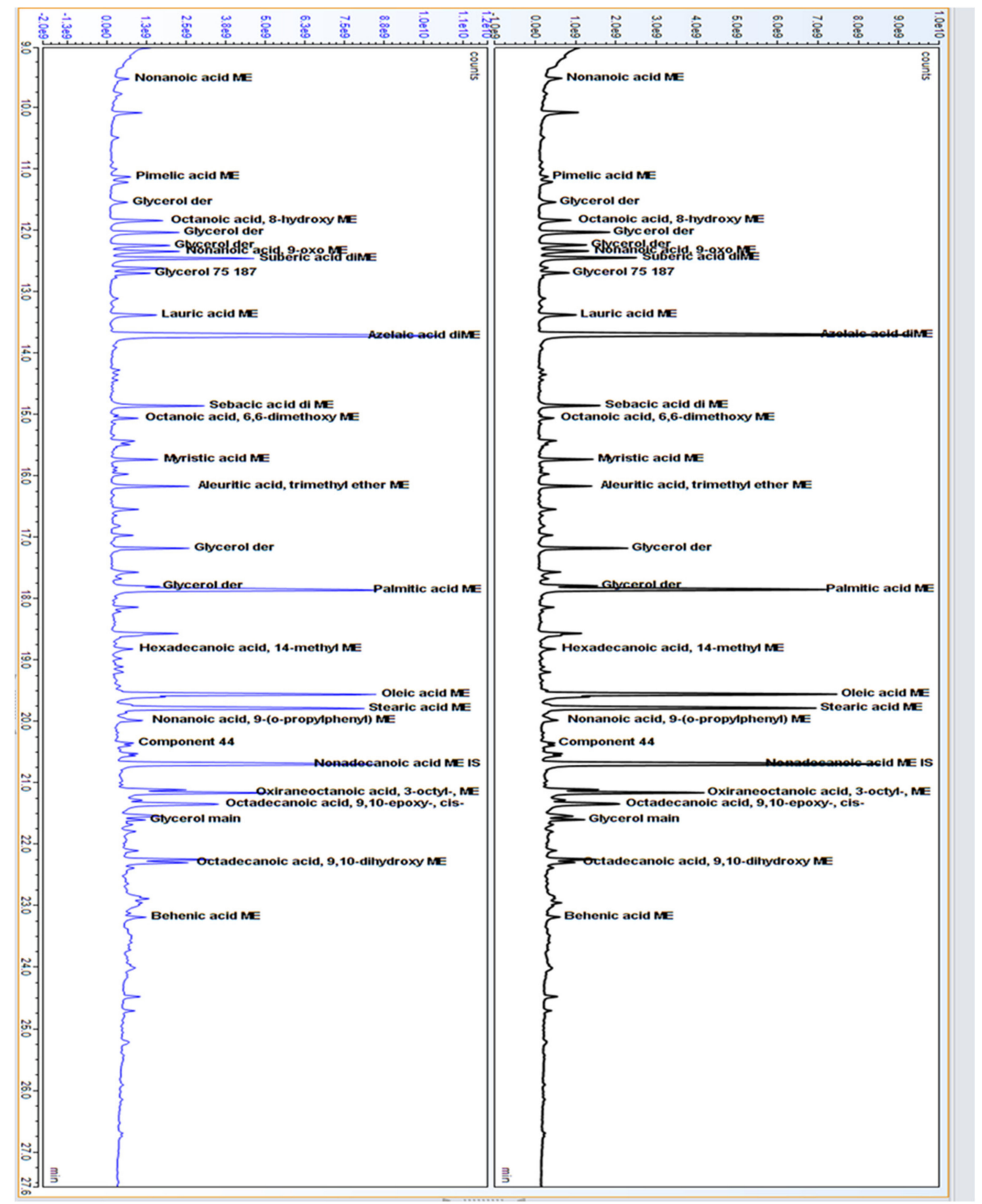

Figure 9. Total ion current (TIC) chromatogram of F-AI replica paint from 2019 (right) and 2021 (left) after derivatisation and GC-MS analysis. Fatty acids were identified as methyl esters (ME) or dimethyl esters (diME); glycerol was identified in different derivatives.

Among the drying oil components, some cyclic compounds were detected as well, namely 7-(o-pentylphenyl)-heptanoic acid and 9-(o-propylphenyl)-nonanoic acid. These are likely the cyclisation products due to the oil prepolymerisation, typically identified in 
stand oils [71]. Stand oil, indeed, was used in the paint replica formulation. So was tung oil, but triple unsaturation cannot be detected with GC-MS.

\subsubsection{Accelerated Ageing}

Paint replica samples (P1 and P2) were accelerated aged in a climate chamber (as described in Section 2.2.2) and the effect of the weathering was assessed though physical and chemical analysis. As for F-AI and F-AP replicas, macroscopic observations, contact angle measurements (wettability), ER-FTIR and GC-MS analysis were performed together with surface profile measurements, tape tests, hardness measurements and colourimetric measurements.

The results from the physical testing are shown in Table 2. Macroscopically speaking, no visible damage such as blistering, cracking, delamination or paint losses were seen in any replica (Figure 10). Surface profile measurements $\left(R_{a}\right)$ did not reveal significant changes in any sample (results are not presented). However, the paints all lost their shine and gloss, and became slightly darker and yellower. The NCS-gloss scale comparator was used, but also assessed by visual observation. These colour variations, visible even to the naked eye, were determined by colourimetric analysis. It was observed that, in both replica paints, the ageing conditions determined a strong variation mainly associated with the parameter L (corresponding to luminosity and ranging from white to black scale). After Ageing 1, L significantly increased (compared to solid unaged reference) in both P1 and P2, with a $\Delta \mathrm{L}$ of 10 and 12 respectively. The $\mathrm{L}$ values, then, decreased in the second ageing step. In Ageing 2, the parameter $\mathrm{b}$ (related to yellow $\rightarrow$ blue scale) increased, with a $\Delta \mathrm{b}$ of 2.7 and 3.9 for P1 and P2, respectively. Thus, the yellowing was more pronounced in the paint formulations containing a mixture of double-boiled linseed oil, stand linseed oil and tung oil: this was likely related to the higher amount of (triply) unsaturated fatty acids present in the fresh oil P1 formulations compared to P2, where the binder was air-blown cold-pressed linseed oil. Finally, the $\Delta \mathrm{E}$, the total colour variations, were higher than 5 in all measured cases, so easily perceived by the naked eye.

Table 2. Summary of physical properties as a function of artificial ageing.

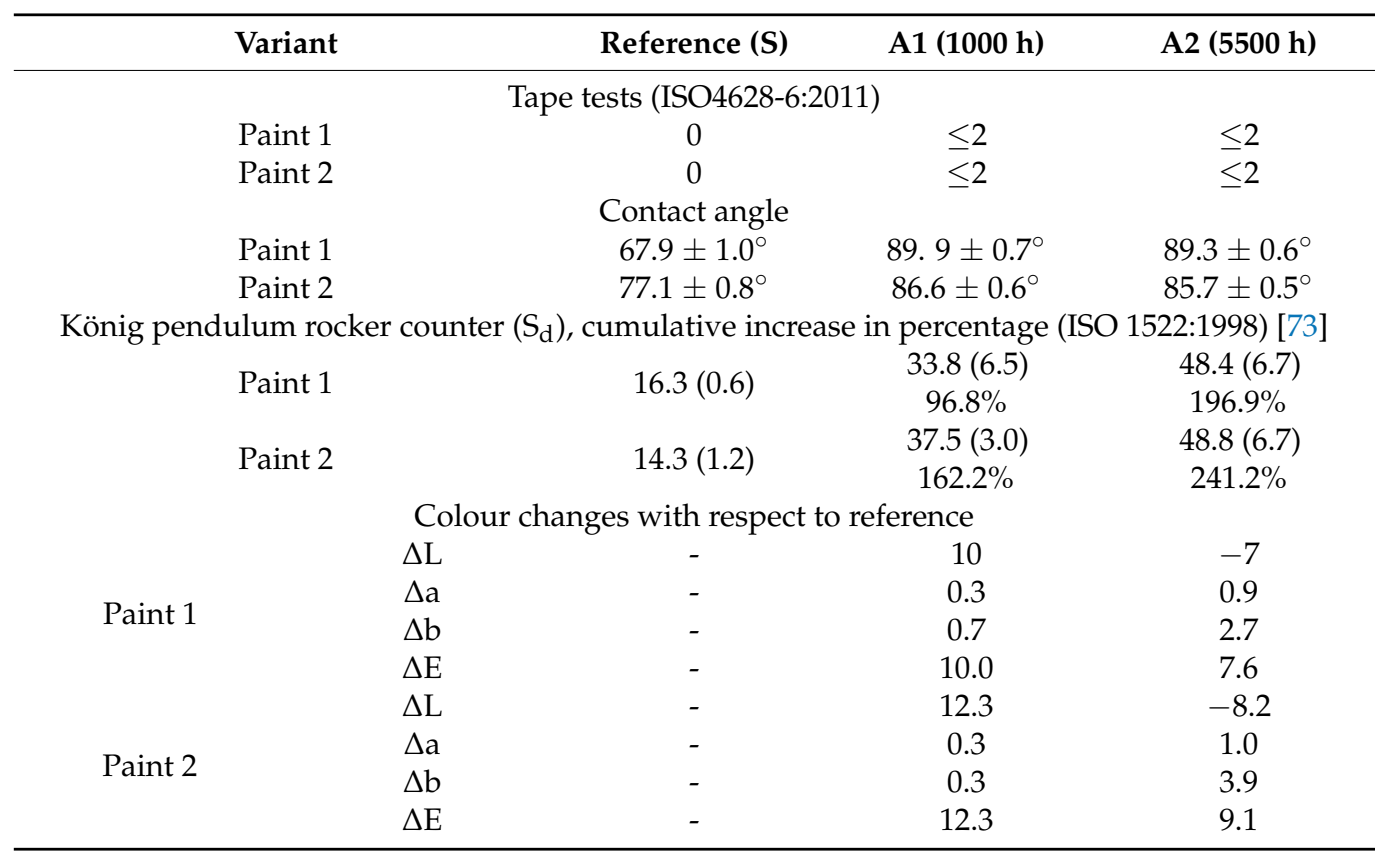

Both paints were very similar in hardness after $5500 \mathrm{~h}$ exposure and very similar hardness was present in both paint replicas at the end of the ageing. The largest increase in hardness (in percentage), i.e., ageing and embrittlement rate during ageing was observed for P2. The tape tests for revealing chalking corresponded to below 2 in the pictorial rate 
according to ISO 4628-6:2011, which suggests a low chalking tendency. As observed in the case of the F-AI and F-AP replicas, also in the P1 and P2 paints the wettability, i.e., the contact angle shifted from values of $68^{\circ}$ and $77^{\circ}$ for the solid unaged reference to values higher than $85^{\circ}$ after the two ageing steps. The wetting angle (as also described by [66] was initially higher for P2, that had the oil mixture binder containing tung oil (Table 2). After ageing this shifted, and the contact angle was slightly higher for P1 with the blown oil varnish. The causes are not known, but the blown oils are known for having high wettability to pigments $[9,14]$, and this may have affected the leafing characteristics and the amount of surface binder. P1 was less viscous than P2 which was noticeable at the application since the brushing required less effort and the surface as a result was smoother.
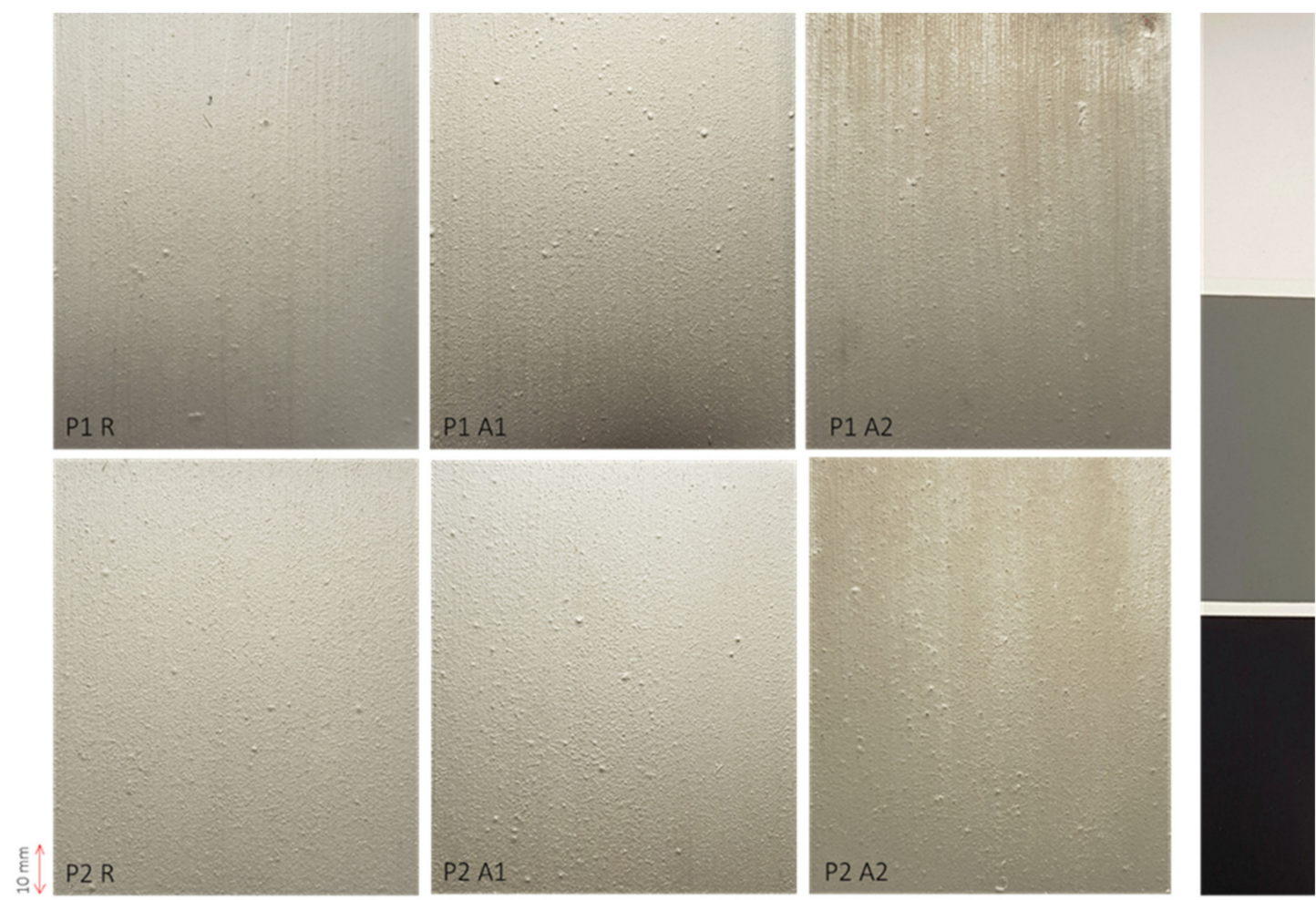

Figure 10. Photographic images of replica armour paints following artificially ageing. A $3 \times$ greyscale QP card was used during photography (on right). R: reference (not aged), A1: $1000 \mathrm{~h}$ ageing and A2: $5500 \mathrm{~h}$. R and A1 for both replica paints only show slight differences in surface appearance compared to sample A2. The A2 sample show markedly greater variation in the surface texture with more clearly apparent vertical brushstrokes. The coarse surface spots are the MIO particles.

In contrast to the analysis of historical samples, ER-FTIR analysis of artificially aged armour paints yielded no detectable signal from the binding medium, which could be as a consequence of the oxidation of the surface of the armour paints, as well as the increased diffusion of infrared signal from the reflective paint surfaces. Instead, FTIR spectra recorded in ATR mode from micro-samples scraped from the top surface revealed a stronger signal from the lipid binder in unaged paints (with weak bands at $1740 \mathrm{~cm}^{-1}$ attributed to $\mathrm{C}=\mathrm{O}$ stretching, and typical $\mathrm{C}-\mathrm{H}$ bending at 2850 and $2920 \mathrm{~cm}^{-1}$ ). Other bands in the FTIR spectra are attributed to inorganic components in the armour paint, as seen in Figures 7 and 8 (see paint formulations in Appendix A).

As observed with the natural aged replica paints, accelerated ageing produced chemical changes which were recorded and quantified by GC-MS analysis. In particular:

- the increase of azelaic acid (especially compared to palmitic acid, A/P ratios) and dicarboxylic acids in general $(\% \mathrm{D})$;

- the decrease of unsaturated fatty acids, specifically oleic, linoleic and linolenic acids for P1 and oleic, linoleic and $\alpha$-eleosteric acid for P2. 
GC-MS analysis highlighted the presence of cyclic compounds typical in stand oil, as seen for F-AI and F-AP replicas, while the presence of tung oil was assessed only on the solid reference of P2 before ageing. Indeed, $\alpha$-eleostearic acid, the characteristic and most abundant triply unsaturated fatty acid in tung oil, was detected only in the unaged paint samples. Due to its susceptibility to cross-linking, this acid is hard to identify in paints that have been subjected to UV exposure, auto-oxidation and degradation processes [12].

\section{Conclusions}

A number of replica armour paints were made based on historical descriptions, with lamellar and highly reflexive pigments of $\mathrm{MIO}$ and metallic leafing aluminium, reactive zinc oxide, in linseed oil and linseed oil-tung oil mixtures. Naturally aged replica paints F-Al and F-AP were compared to the historical armour paints and the artificially aged replica armour paints $\mathrm{P} 1$ and $\mathrm{P} 2$ with a multianalytical approach.

The historical paint formulations included linseed oil binders, but since an aged tung oil proportion cannot be easily detected due to the rapid oxidation occurring for $\alpha$ eleostearic acid (the most abundant unsaturated fatty acid in tung oil), we cannot confirm or exclude that tung oil was used. One of the historical armour paints had alkyd binders, over a red hematite linseed oil primer (not red lead linseed oil primer, which was usual). It is possible to distinguish stand oils in replica paints, due to the presence of cyclic compounds, but stand oils were not detected in the historical paints.

The first visible sign of ageing is loss of gloss and hardly noticeable chalking, as seen in results of the tape tests. The replica armour paints showed matte, slightly chalking surfaces and slight discolouration due to the accelerated exposure, but no signs of cracking, flaking or under film corrosion, after the test period. The results likely confirm that the pigments formed a physical barrier and thus retarded photo-oxidation and hydrolysis of binder, as suggested by [6]. The leafing effect of aluminium pigments led to only a small concentration of binder at the surface, as revealed by ER-FTIR and ATR-FTIR analysis. Chemical changes still occurred below the surface of the naturally aged samples, as observed by GC-MS analysis. The surface was hydrophobic (or slightly wetted) for all replica paints, but the mechanisms of surface ageing and the reason for changes in wettability are not fully understood. It seems likely that the surface oxidation was not complete. The increased yellowing of P2 is ascribed to the higher number of triply unsaturated fatty acids in the binder mixture.

The accelerated ageing of $5500 \mathrm{~h}$ according to international standard ISO 16474-2 [74] corresponds to approximately four years of natural ageing in Southern Sweden. The GCMS results (from bulk analysis) suggest that, following the ageing methods (natural or accelerated) adopted in this study, the replica paints presented considerable percentages of unsaturation, which is considered to be normal given the young age of the paint films and the influence that metallic pigments can have. In the same way it is possible to explain the behaviour of paints in terms of wettability. Therefore, it will be necessary to continue with constant monitoring to see the behaviour of these paints over time.

We conclude that both the oil paint mixtures used in paint formulations as part of this research were suitable for the production of armour paints that are in many respects similar to the historical paints. Nonetheless the long-term evaluation of ageing of these complex paints requires longer exposure and methods for the determination of failure of the paints as protectives. It is likely that paint formulations need adjustments in order to modify paint body and application performance. Future research should explore the role of the aluminium flakes and the extent to which their geometry influences the formation of a barrier film, and the role of zinc white as an additive to the paints.

Author Contributions: A.K.: conceptualization, project administration, investigation, methodology, formal analysis, visualization, writing - original draft, review and editing. A.N.: methodology, formal analysis, visualization, writing-review and editing, supervision. F.C.I.: investigation, methodology, formal analysis, visualization, writing - review and editing. All authors have read and agreed to the published version of the manuscript. 
Funding: This research received no external funding.

Institutional Review Board Statement: This study involves no humans or animals. The study was conducted according to the guidelines of the Declaration.

Informed Consent Statement: Not applicable.

Data Availability Statement: Data from this study is available at request from the authors.

Conflicts of Interest: The authors declare no conflict of interest.

\section{Appendix A}

Table A1. Replica Paint Formulations (wt. \%).

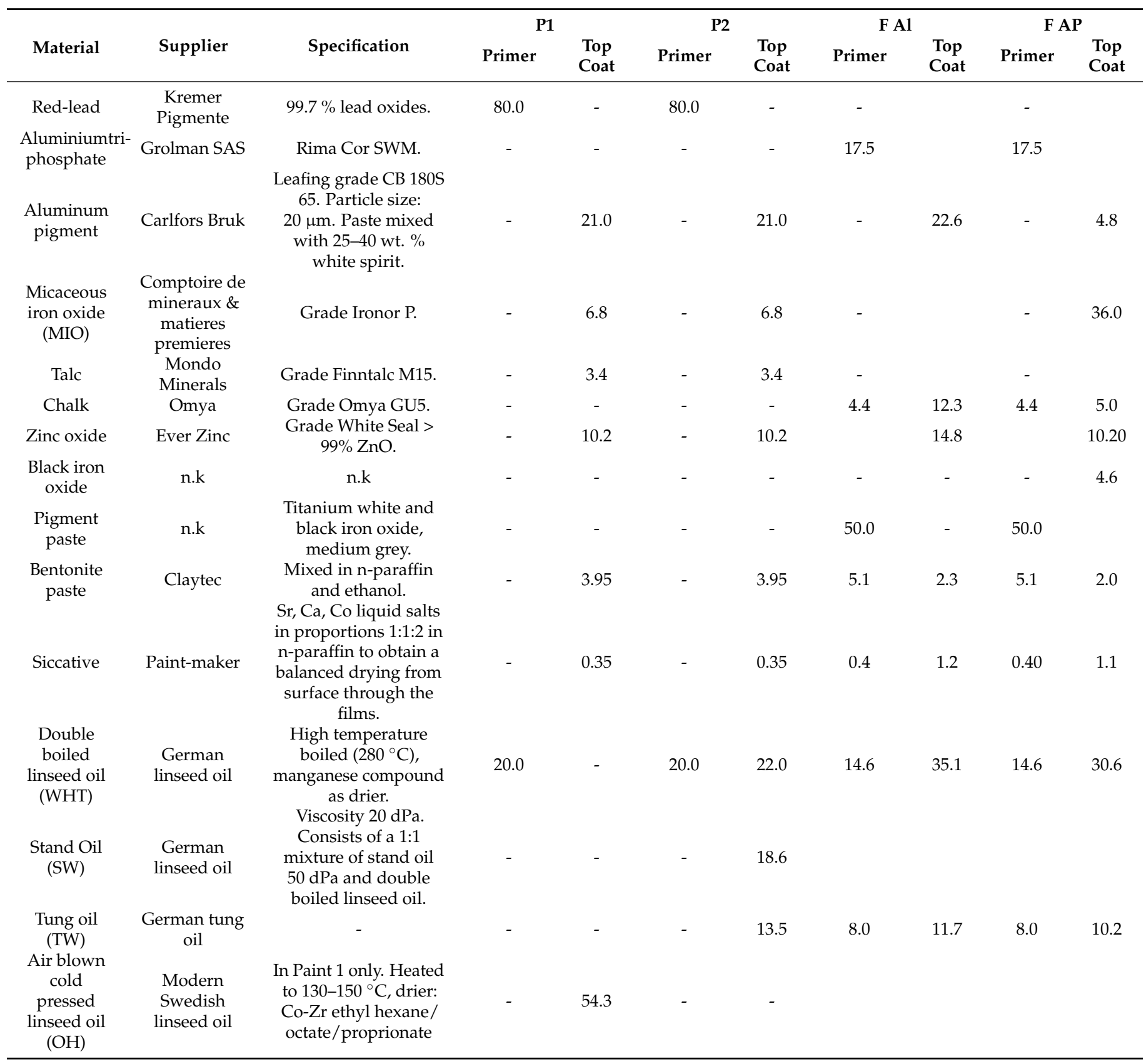




\section{Appendix B}

Table A2. Fatty Acid Profiles (at \%) and Fatty Acid Molar Ratios.

\begin{tabular}{|c|c|c|c|c|c|c|c|c|c|c|c|c|c|c|c|}
\hline & & \multicolumn{14}{|c|}{ Paintings and Paint Samples } \\
\hline & & \multicolumn{4}{|c|}{ Historical Paints } & \multicolumn{6}{|c|}{ Paint Recipes } & \multicolumn{2}{|c|}{ Field Exposed } & \multirow{3}{*}{ F AP2019 } & \multirow{3}{*}{ F AP202 } \\
\hline & & \multirow[t]{2}{*}{ OM } & \multirow[t]{2}{*}{ GMW } & \multirow[t]{2}{*}{ BJ Grey } & \multirow[t]{2}{*}{ BJ Red } & \multicolumn{3}{|c|}{ BWP1 } & \multicolumn{3}{|c|}{ BWP3 } & \multirow{2}{*}{ F AI2019 } & \multirow{2}{*}{ F AI2021 } & & \\
\hline & & & & & & $\mathrm{S}$ & A1 & A2 & $\mathrm{S}$ & A1 & A2 & & & & \\
\hline \multirow{18}{*}{ 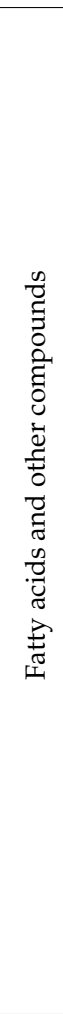 } & Glycerol & 8.6 & 6.2 & 11.5 & 10.5 & 16.8 & 14.8 & 6.6 & 10.0 & 9.2 & 10.5 & 12.1 & 9.2 & 11 & 11.2 \\
\hline & Pimelic acid & 0.8 & 1.8 & 1 & 0.5 & 1.0 & 0.5 & 0.8 & 0.9 & 0.4 & 0.8 & 0.4 & 1.0 & 0.6 & 0.9 \\
\hline & Suberic acid & 5.6 & 8.8 & 4.4 & 5.9 & 3.5 & 5.7 & 6.1 & 3.1 & 4.2 & 6.2 & 4.6 & 6.6 & 5.4 & 6.7 \\
\hline & Azelaic acid & 27.9 & 26 & 26.6 & 38.8 & 24.3 & 32.5 & 31.3 & 23.5 & 26.8 & 34.9 & 22.9 & 25.0 & 21.0 & 26.9 \\
\hline & Sebacic acid & 2.5 & 3.4 & 3 & 3 & 1.6 & 2.9 & 3.4 & 1.6 & 2.0 & 2.9 & 2.9 & 4.1 & 4.0 & 5.5 \\
\hline & Myristic acid & 3.2 & 3.1 & 1.4 & 1.1 & 5.3 & 6.4 & 4.6 & 6.2 & 5.0 & 4.2 & 2.2 & 2.0 & 2.0 & 2.2 \\
\hline & Palmitic acid & 23.8 & 16.9 & 24.9 & 22.2 & 19.9 & 23.9 & 21.9 & 22.8 & 20.9 & 17.7 & 17.7 & 18.6 & 16.8 & 22.0 \\
\hline & Stearic acid & 21.3 & 32.9 & 18.6 & 15.1 & 16.7 & 18.5 & 16.7 & 19.8 & 18.9 & 15.8 & 16.4 & 15.4 & 14.3 & 17.3 \\
\hline & Oleic acid & 5.9 & 0.4 & 7.5 & 1.6 & 9.9 & 9.1 & 8.2 & 10.9 & 11.0 & 6.5 & 17.9 & 15.3 & 20.1 & 19.6 \\
\hline & Linoleic acid & 0.5 & 0.6 & 1.1 & 1.3 & 1.0 & 0.4 & 0.4 & 1.2 & 1.7 & 0.5 & 0.3 & 0.1 & 0.4 & 0.3 \\
\hline & Linolenic acid & & & & & $x$ & & & & & & & & & \\
\hline & $\begin{array}{l}\text { Nonanoic acid, } \\
\text { 9-(o-propylphenyl)- }\end{array}$ & & & & & & & & $\mathrm{x}$ & $\mathrm{x}$ & $\mathrm{x}$ & $\mathrm{x}$ & $\mathrm{x}$ & $\mathrm{x}$ & $\mathrm{x}$ \\
\hline & $\begin{array}{c}\text { Heptanoic acid } \\
\text { 7-(o-pentylphenyl)- }\end{array}$ & & & & & & & & $\mathrm{x}$ & $\mathrm{x}$ & $\mathrm{x}$ & $\mathrm{x}$ & $\mathrm{x}$ & $\mathrm{x}$ & $\mathrm{x}$ \\
\hline & Phthalic acid & & & $\mathrm{x}$ & & & & & & & & & & & \\
\hline & Pentaerytritol & & & $\mathrm{x}$ & & & & & & & & & & & \\
\hline & Benzoic acid & & & $x$ & & & & & & & & & & & \\
\hline & Arachidic acid & & & & & & & & & & & $x$ & $\mathrm{x}$ & $x$ & $\mathrm{x}$ \\
\hline & Behenic acid & & & & & & & & & & & $\mathrm{x}$ & $\mathrm{x}$ & $x$ & $\mathrm{x}$ \\
\hline
\end{tabular}


Table A2. Cont.

\begin{tabular}{|c|c|c|c|c|c|c|c|c|c|c|c|c|c|c|c|}
\hline & & \multicolumn{14}{|c|}{ Paintings and Paint Samples } \\
\hline & & \multicolumn{4}{|c|}{ Historical Paints } & \multicolumn{6}{|c|}{ Paint Recipes } & \multicolumn{2}{|c|}{ Field Exposed } & \multirow{3}{*}{ F AP2019 } & \multirow{3}{*}{ F AP2021 } \\
\hline & & \multirow[t]{2}{*}{ OM } & \multirow[t]{2}{*}{ GMW } & \multirow[t]{2}{*}{ BJ Grey } & \multirow[t]{2}{*}{ BJ Red } & \multicolumn{3}{|c|}{ BWP1 } & \multicolumn{3}{|c|}{ BWP3 } & \multirow{2}{*}{ F AI2019 } & \multirow{2}{*}{ F AI2021 } & & \\
\hline & & & & & & $\mathrm{S}$ & A1 & A2 & $\mathrm{S}$ & A1 & A2 & & & & \\
\hline & Dehydroabietic acid & $\mathrm{x}$ & & $\mathrm{x}$ & & & & & & & & & & & \\
\hline & $\begin{array}{l}\text { Octadecanoic acid, } \\
\text { 9,10-dihydroxy-, }\end{array}$ & $\mathrm{x}$ & $\mathrm{x}$ & $\mathrm{x}$ & $\mathrm{x}$ & $\mathrm{x}$ & $\mathrm{x}$ & $\mathrm{x}$ & $\mathrm{x}$ & $\mathrm{x}$ & $\mathrm{x}$ & $\mathrm{x}$ & $\mathrm{x}$ & $\mathrm{x}$ & $\mathrm{x}$ \\
\hline & $\begin{array}{l}\text { hydroxy-and methoxy- } \\
\text { octadecanoic acids }\end{array}$ & $\mathrm{x}$ & $\mathrm{x}$ & $\mathrm{x}$ & $\mathrm{x}$ & $\mathrm{x}$ & $\mathrm{x}$ & $\mathrm{x}$ & $\mathrm{x}$ & $\mathrm{x}$ & $\mathrm{x}$ & $\mathrm{x}$ & $\mathrm{x}$ & $\mathrm{x}$ & $\mathrm{x}$ \\
\hline \multirow{5}{*}{ 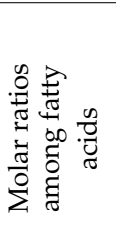 } & $\mathrm{P} / \mathrm{S}$ & 1.1 & 0.5 & 1.3 & 1.5 & 1.3 & 1.3 & 1.3 & 1.2 & 1.1 & 1.1 & 1.2 & 1.2 & 1.2 & 1.2 \\
\hline & $\mathrm{A} / \mathrm{P}$ & 1.2 & 1.5 & 1.1 & 1.7 & 1.2 & 1.4 & 1.4 & 1.0 & 1.3 & 2.0 & 1.3 & 1.3 & 1.2 & 1.2 \\
\hline & $\mathrm{D} / \mathrm{P}$ & 1.5 & 2.3 & 1.4 & 2.1 & 1.5 & 1.7 & 1.9 & 1.2 & 1.6 & 2.5 & 1.7 & 1.9 & 1.8 & 1.8 \\
\hline & $\% \mathrm{D}$ & 36.7 & 39.9 & 35 & 48.2 & 30.4 & 41.7 & 41.6 & 29.1 & 33.4 & 44.8 & 30.9 & 36.7 & 31.0 & 40.0 \\
\hline & $\mathrm{O} / \mathrm{S}$ & 0.3 & $<<0.1$ & 0.4 & 0.1 & 0.6 & 0.5 & 0.5 & 0.6 & 0.6 & 0.4 & 1.1 & 1.0 & 1.4 & 1.1 \\
\hline
\end{tabular}




\section{References}

1. Källbom, A.; Almevik, G. Maintenance of Painted Steel Sheet Roofs on Historic Buildings in Sweden. Int. J. Archit. Herit. 2020, 14, 1-16. [CrossRef]

2. Reuterswärd, P. Optimal Skötsel av Stålbroar. [Optimal Care of Steel Bridges]; Research Report 2010-130; Swerea KIMAB: Stockholm, Sweden, 2011.

3. Reuterswärd, P. Ommålning av Kvarnsilos på Kvarnholmen 2013. [Repainting of Mill Silos at Kvarnholmen 2013]; Research Report; Swerea KIMAB: Stockholm, Sweden, 2013.

4. IVA (The Royal Swedish Academy of Engineering Sciences, Corrosion Committee). Målning av Järnkonstruktioner Utsatta för Atmosfärens Inverkan. Meddelande nr 1. [Painting of Steel Constructions Exposed to Atmospheric Impact. Message no 1.]; Ingenjörsvetenskapakademien: Stockholm, Sweden, 1935.

5. IVA (The Royal Swedish Academy of Engineering Sciences, Corrosion Committee). Handbok I Rostskyddsmålning av Stålkonstruktioner Utsatta för Atmosfärens Inverkan. [Handbook in Anticorrosive Painting of Steel Constructions Exposed to the Atmosphere]; Ingenjörsvetenskapsakademien: Stockholm, Sweden, 1961.

6. Edwards, J.D. Aluminum Paint and Powders, 1st ed.; Reinhold Publishing Corporation: New York, NY, USA, 1936.

7. Holland, A. Decorative and functional metallic effect pigments. Paint Coat. Ind. 2016, 32, 82-84.

8. Jordan, L. Tung oil. Particularly referring to the possibilities of production within the British Empire, with a bibliography of the literature. J. Soc. Chem. Ind. 1929, 48, 847-859. [CrossRef]

9. Standeven, H. House Paints, 1900-1960: History and Use; Getty Conservation Institute: Los Angeles, CA, USA, 2011.

10. Ling, T.T.; Rhodes, F.H. The Oxidation of Chinese Wood Oil. Ind. Eng. Chem. 1925, 17, 508-512.

11. Hilditch, T.P.; Mendelowitz, A. The component fatty acids and glycerides of tung oil. J. Sci. Food Agric. 1951, 2, 548-556. [CrossRef]

12. Schönemann, A.; Frenzel, W.; Unger, A.; Kenndler, E. An Investigation of the Fatty Acid Composition of New and Aged Tung Oil. Stud. Conserv. 2006, 51, 99-110. [CrossRef]

13. Suida, H.; Salvaterra, H. Rostschutz Und Rostschutzanstrich; Technisch-Gewerbliche, B., Wien, J., Eds.; Springer: Berlin, Germany, 1931; Volume 6.

14. Singer, E. Fundamentals of Paints, Varnish and Lacquer Technology; The American Paint Journal Company: Washington, DC, USA, 1957.

15. Sabin, A.H. Industrial and Artistic Technology of Paint and Varnish; John Wiley \& Sons: New York, NY, USA, 1927.

16. Nylén, P. Färger, lacker och fernissor. [Paints, lacquers and varnishes]. In Handbok i Kemisk Teknologi. Band III. Red; Angel, G., Ed.; Natur och Kultur: Stockholm, Sweden, 1948.

17. Crebert, T.H. Eigenschaften und Eigenarten von Lyftoxydiertem Leinöl, eine Übersicht. Fette Und Seife 1938, 45, 676. [CrossRef]

18. Stenberg, C. Influence of the Fatty Acid Pattern on the Drying of Linseed Oils. Ph.D. Thesis, KTH Royal Institute of Technology, Stockholm, Sweden, 2004.

19. Kalpers, H. Der Anstrich aus Aluminium. Dingler Polytech. J. 1930, 345, 64-67.

20. Bayliss, D.; Deacon, D. Steelwork Corrosion Control, 2nd ed.; Spon Press: London, UK, 2002.

21. Brock, T.; Groteklaes, M.; Mischke, P. European Coatings Handbook; Curt R Vincent Verlag: Hanover, Germany, 2002.

22. Forsgren, M. Corrosion Control Through Organic Coatings; CRC Press: Boca Raton, FL, USA, 2006.

23. Sørensen, P.; Kiil, A.; Dam-Johansen, S.; Weinell, K. Anticorrosive coatings: A review. J. Coat. Technol. Res. 2009, 6, 135-176. [CrossRef]

24. Talbert, R. Paint Technology Handbook; CRC Press: Boca Raton, FL, USA, 2008.

25. Malshe, V.; Waghoo, G. Chalk resistant epoxy resins. Prog. Org. Coat. 2004, 51, 172-180. [CrossRef]

26. Tcharkhtchi, A.; Farzaneh, S.; Abdallah-Elhirtsi, S.; Esmaeillou, B.; Nony, F.; Baron, A. Thermal Aging Effect on Mechanical Properties of Polyurethane. Int. J. Polym. Anal. Charact. 2014, 19, 571-584. [CrossRef]

27. International Council on Monuments and Sites. The Nara Document on Authenticity; ICOMOS: Nara, Japan, 1994.

28. International Council on Monuments and Sites. ICOMOS Charter-Principles for the Analysis, Conservation and Structural Restoration of Architectural Heritage; ICOMOS: Victoria Falls, Zambia, 2003.

29. International Council on Monuments and Sites. European Quality Principles for EU-Funded Interventions with Potential Impact Upon Cultural Heritage; ICOMOS: Paris, France, 2019.

30. Araujo, W.S.; Margarit, I.C.P.; Mattos, O.R.; Fragata, F.L.; de Lima-Neto, P. Corrosion Aspects of Alkyd Paints Modified with Linseed and Soy Oils. Electrochim. Acta 2010, 55, 6204-6211. [CrossRef]

31. Behzadnasab, M.; Mirabedini, S.M.; Esfandeh, M.; Farnood, R.R. Evaluation of Corrosion Performance of a Self-healing Epoxybased Coating Containing Linseed Oil-filled Microcapsules via Electrochemical Impedance Spectroscopy. Prog. Org. Coat. 2017, 105, 212-224. [CrossRef]

32. Ahmad, S.; Ashraf, S.; Zafar, F. Development of linseed oil based polyesteramide without organic solvent at lower temperature. J. Appl. Polym. Sci. 2007, 104, 1143-1148. [CrossRef]

33. Xia, Y.; Larock, R. Vegetable oil-based polymeric materials: Synthesis, properties, and applications. Green Chem. 2010, 12, 1893-1909. [CrossRef]

34. Alam, M.; Akram, D.; Sharmin, E.; Zafar, F.; Ahmad, S. Vegetable oil based eco-friendly coating materials: A review article. Arab. J. Chem. 2014, 7, 469-479. [CrossRef] 
35. Wissling, P. Metallic Effect Pigments. In European Coatings Literature; Vincentz Network: Hannover, Germany, 2006.

36. Wei, L.; Haiping, Z.; Yuanyuan, S.; Hui, Z.; Jesse, Z. Preparation of aluminium metallic pigmented powder coatings with high color stability using a novel method: Microwave bonding. Prog. Org. Coat. 2020, 147, 105787.

37. Gao, A.; Pi, P.; Wen, X.; Zheng, D.; Cai, Z.; Cheng, J.; Yang, Z. Preparation and characterisation of aluminium pigments encapsulated by composite layer containing organic silane acrylate resin and SiO2. Pigment Resin Technol. 2012, 41, 149-155. [CrossRef]

38. Babcock, G.M.; Painfield, N.J.; Retwish, F.B.; Woolsey, W.P. Stabilised Vehicles for Leafing Aluminium Coatings. U.S. Patent 2904525, 15 September 1959.

39. Kotlík, P.; Doubravová, K.; Horálek, J.; Kubáč, L.; Akrman, J. Acrylic copolymer coatings for protection against UV rays. J. Cult. Herit. 2014, 15, 44-48. [CrossRef]

40. Scalarone, D.; Lazzari, M.; Chiantore, O. Thermally assisted hydrolysis and methylation-pyrolysis-gas chromatography/mass spectrometry of light-aged linseed oil. J. Anal. Appl. Pyrolysis 2001, 58, 503-512. [CrossRef]

41. Izzo, F.C.; Balliana, E.; Pinton, F.; Zendri, E. A preliminary study of the composition of commercial oil, acrylic and vinyl paints and their behaviour after accelerated ageing conditions. Conserv. Sci. Cult. Herit. 2014, 14, 353-369.

42. Berg, J.; Van den Berg, K.J.; Boon, J. Chemical changes in curing and ageing oil paints. In Proceedings of the 12th Triennial Meeting, Lyon, France, 29 August-3 September 1999; pp. 248-253.

43. van den Berg, J.D.; Van den Berg, K.J.; Boon, J.J. Identification of non-cross-linked compounds in methanolic extracts of cured and aged linseed oil-based paint films using gas chromatography-mass spectrometry. J. Chromatogr. A 2002, 950, 195-211. [CrossRef]

44. Erhardt, D.; Tumosa, C.S.; Mecklenburg, M.F. Long-Term Chemical and Physical Processes in Oil Paint Films. Stud. Conserv. 2005, 50, 143-150. [CrossRef]

45. Erhardt, D.; Tumosa, C.S.; Mecklenburg, M. Natural and accelerated thermal aging of oil paint films. Stud. Conserv. 2000, 45, 65-69. [CrossRef]

46. Lazzari, M.; Chiantore, Q. Drying and oxidative degradation of linseed oil. Polym. Degrad. Stab. 1999, 65, 303-313. [CrossRef]

47. Fuster-López, L.; Izzo, F.C.; Piovesan, M.; Sperni, L.; Zendri, E. Study of the chemical composition and the mechanical behaviour of 20th century commercial artists' oil paints containing manganese-based pigments. Microchem. J. 2016, 124, 962-973. [CrossRef]

48. International Organization for Standardization. ISO 2178:2016: Non-Magnetic Coatings on Magnetic Substrates-Measurement of Coating Thickness-Magnetic Method; International Organization for Standardization: Geneva, Switzerland, 2016.

49. International Organization for Standardization. ISO 4287:1997: Geometrical Product Specifications (GPS)—Surface Texture: Profile Method-Terms, Definitions and Surface Texture Parameters; International Organization for Standardization: Genève, Switzerland, 1997.

50. International Organization for Standardization. ISO 12944-2:1998: Paints and Varnishes—Corrosion Protection of Steel Structures by Protective Paint Systems-Part 2: Classification of Environments; International Organization for Standardization: Geneva, Switzerland, 1998.

51. Atlas. Weathering Testing Guidebook; Atlas Material Testing Solutions: Chicago, IL, USA, 2001.

52. Wernståhl, K. Jämförelser Mellan Ljusdoser Vid Naturlig Och Accelererad Väderexponering. [Comparison between Light Doses at Natural and Accelerated Weather Exposure]; SP Ytskydd och korrosion (RISE): Borås, Sweden, 1993.

53. International Organization for Standardization. ISO 4628-6:2011: Paints and Varnishes-Evaluation of Degradation of CoatingsDesignation of Quantity and Size of Defects, and of Intensity of Uniform Changes in Appearance-Part 6: Assessment of Degree of Chalking by Tape Method; International Organization for Standardization: Geneva, Switzerland, 2011.

54. Irigoyen, M.; Bartolomeo, P.; Perrin, F.X.; Aragon, E.; Vernet, J.L. UV ageing characterisation of organic anticorrosion coatings by dynamic mechanical analysis, Vickers microhardness, and infra-red analysis. Polym. Degrad. Stab. 2001, 74, 59-67. [CrossRef]

55. Ma, X.; Qiao, Z.; Huang, Z.; Jing, X. The dependence of pendulum hardness on the thickness of acrylic coating. J. Coat. Technol. Res. 2013, 10, 433-439. [CrossRef]

56. Izzo, F. 20th Century Artists' Oil Paints: A Chemical-Physical Survey. Ph.D. Thesis, University “Ca' Foscari”, Venice, Italy, 2011.

57. Izzo, F.C.; van den Berg, K.J.; van Keulen, H.; Ferriani, B.; Zendri, E. Modern Oil Paints—Formulations, Organic Additives and Degradation: Some Case Studies. In Issues in Contemporary Oil Paint; van den Berg, K.J., Burnstock, A., de Keijzer, M., Krueger, J., Learner, T., Tagle, A., Heydenreich, d., Eds.; Springer: Cham, Switzerland, 2014. [CrossRef]

58. Izzo, F.C.; Zanin, C.; van Keulen, H.; Da Roit, C. From pigments to paints: Studying original materials from the atelier of the artist Mariano Fortuny y Madrazo. Int. J. Conserv. Sci. 2017, 8, 547-564.

59. Caravá, S.; García, C.R.; de Agredos-Pascual, M.L.V.; Mascarós, S.M.; Izzo, F. Investigation of modern oil paints through a physico-chemical integrated approach. Emblematic cases from Valencia, Spain. Spectrochim. Acta. Part A Mol. Biomol. Spectrosc. 2020, 240, 118633. [CrossRef]

60. Fuster-López, L.; Izzo, F.; Damato, V.; Yusà-Marco, D.; Zendri, E. An insight into the mechanical properties of selected commercial oil and alkyd paint films containing cobalt blue. J. Cult. Herit. 2019, 35, 225-234. [CrossRef]

61. Fuster-López, L.; Izzo, F.C.; Andersen, C.K.; Murray, A.; Vila, A.; Picollo, M.; Stefani, L.; Jiménez, R.; Aguado-Guardiola, E. Picasso's 1917 paint materials and their influence on the condition of four paintings. SN Appl. Sci. 2020, 2, 1-14. [CrossRef]

62. Hermans, J.J.; Keune, K.; Van Loon, A.; Iedema, P.D. Toward a complete molecular model for the formation of metal soaps in oil paints. In Metal Soaps in Art; Springer: Cham, Switzerland, 2019. 
63. Boon, J.J.; Hoogland, F.; Keune, K. Chemical processes in aged oil paints affecting metal soap migration and aggregation. In Proceedings of the AIC Annual Meeting, Providence, RI, USA, 16-19 June 2006.

64. Keune, K.; Boon, J.J. Analytical Imaging studies of cross-sections of paintings affected by lead soap aggregate formation. Stud. Conserv. 2007, 52, 161-176. [CrossRef]

65. Ploeger, R.; Scalarone, D.; Chiantore, O. he characterization of commercial artists' alkyd paints. J. Cult. Herit. 2008, 9, 412-419. [CrossRef]

66. Arminger, B.; Jaxel, J.; Bacher, M.; Gindl-Altmutter, W.; Hansmann, C. On the drying behavior of natural oils used for solid wood finishing. Prog. Org. Coat. 2020, 148, 105831. [CrossRef]

67. Grundke, K.; Pöschel, K.; Synytska, A.; Frenzel, R.; Drechsler, A.; Nitschke, M.; Welzel, P.B. Experimental studies of contact angle hysteresis phenomena on polymer surfaces-Toward the understanding and control of wettability for different applications. Adv. Colloid Interface Sci. 2015, 222, 350-376. [CrossRef]

68. Hansen, D. Fakta om Linoljefärg [Facts about Linseed Oil Paints]. Wibo Färg AB. 2021. Available online: http://www.wibofarg. se/knappar/varfor-linoljefarg/fakta-om-linoljefarg.html (accessed on 9 June 2021).

69. Wexler, H. Polymerization of drying oils. Chem. Rev. 1964, 64, 591-611. [CrossRef]

70. Rogala, D.; Lake, S.; Maines, C.; Mecklenburg, M. Condition Problems Related to Zinc Oxide Underlayers: Examination of Selected Abstract Expressionist Paintings from the Collection of the Hirshhorn Museum and Sculpture Garden, Smithsonian Institution. J. Am. Inst. Conserv. 2010, 49, 96-113. [CrossRef]

71. Osmond, G. Zinc white: A review of zinc oxide pigment properties and implications for stability in oil-based paintings. AICCM Bull. 2012, 33, 20-29. [CrossRef]

72. Sebedio, J.L.; Grandgirard, A. Cyclic fatty acids: Natural sources, formation during heat treatment, synthesis and bio logical properties. Prog. Lipid Res. 1989, 28, 303-336. [CrossRef]

73. International Organization for Standardization. ISO 1522:1998. Paints and Varnishes_Pendulum Damping Test; International Organization for Standardization: Geneva, Switzerland, 1998.

74. International Organization for Standardization. ISO 16474-2:2013. Paints and Varnishes—Methods of Exposure to Laboratory Light Sources. Part 2: Xenon-Arc Lamps; International Organization for Standardization: Geneva, Switzerland, 2013.

\section{Short Biography of Authors}

Arja Källbom, a Ph.D. candidate at Gothenburg University, Department of Conservation, is about to finish her thesis about anticorrosive painting treatments consisting of drying oil varnish paints for the protection of ferrous heritage. She is a metallurgist, building conservator and traditional architectural painter. Källbom works with heritage paints (restoration, repairs and reconstruction), ferrous and non-ferrous metallurgy and metallography (for instance, cast aluminium alloys, stainless steels, wrought iron, fractography) and as consultant in Swedish heritage conservation. She is part-time employed at the Craft Laboratory in Mariestad and works with Nordic pine tars for wooden heritage substrates.

Austin Nevin is the Head of Conservation at the Courtauld Institute of Art and has a Ph.D. (2008) and MA (2004) in the Conservation of Paintings (Wall Paintings) from the Courtauld, and M.Chem. (2001) from the University of Oxford. Prior to joining the Courtauld, he worked at the University of Gothenburg as a Senior Lecturer, and the Italian National Research Council as a Researcher from 2011-2019. His research focuses on the analysis of works of art, particularly paintings on walls and easels, and the development and assessment of conservation treatments. He is the Vice President and a Fellow of the International Institute for the Conservation of Artistic and Historic Works (IIC).

Francesca Caterina Izzo is an Assistant Professor in Heritage and Conservation Science at the Ca' Foscari University of Venice. She gained an MA in "Chemical Sciences and Technologies for the Conservation of Cultural Heritage" at Ca' Foscari University of Venice in 2007; and a European Ph.D. in Chemical Sciences in 2011 with the thesis titled "20th century artists' oil paints: a chemical-physical survey". From 2012 she has been working as an academic researcher in conservation science for contemporary art in Venice, collaborating with several Italian and international organisations and institutions (such as the international gallery of Modern Art Ca' Pesaro of Venice, the Venice Biennale, the Triennale Design Museum of Milan, the Netherlands Cultural Heritage Agency). She collaborates also with restorers, conservators, public and private collections and has been involved in several European projects dealing with the science, education and conservation of cultural heritage. Izzo is on the board of the Italian Chemical Society (SCI) for the division of Chemistry of the Environment and Cultural Heritage and is the head of the SCI working group "Diagnostics for Cultural Heritage" and also a member of AIAr, the Italian Association of Archaeometry, which awarded her the Improta Prize in 2017 as the best young researcher in the field of cultural heritage studies. 